NBER WORKING PAPER SERIES

\title{
HOW EXPORTERS GROW
}

\author{
Doireann Fitzgerald \\ Stefanie Haller \\ Yaniv Yedid-Levi \\ Working Paper 21935 \\ http://www.nber.org/papers/w21935 \\ NATIONAL BUREAU OF ECONOMIC RESEARCH \\ 1050 Massachusetts Avenue \\ Cambridge, MA 02138 \\ January 2016, Revised December 2019
}

This work makes use of data from the Central Statistics Office, Ireland, which is CSO copyright. The possibility for controlled access to confidential micro data sets on the premises of the CSO is provided for in the Statistics Act 1993. The use of CSO data in this work does not imply the endorsement of the CSO in relation to the interpretation or analysis of the data. This work uses research data sets that may not exactly reproduce statistical aggregates published by the CSO. We thank the staff of the CSO for making this project possible. Expert research assistance was provided by Adrian Corcoran, Matt Shapiro and Anthony Priolo. Doireann Fitzgerald is grateful for financial support from the NSF under grant number 0647850. Yaniv Yedid-Levi is grateful for financial support from the Social Sciences and Humanities Research Council of Canada. We thank Manuel Amador, Costas Arkolakis, Tim Kehoe, Kim Ruhl, James Tybout, Daniel Xu, and participants in the 2015 and 2016 NBER Summer Institute for comments and suggestions. The views expressed herein are those of the authors and not necessarily those of the Federal Reserve Bank of Minneapolis, the Federal Reserve System, or the National Bureau of Economic Research.

NBER working papers are circulated for discussion and comment purposes. They have not been peer-reviewed or been subject to the review by the NBER Board of Directors that accompanies official NBER publications.

(C) 2016 by Doireann Fitzgerald, Stefanie Haller, and Yaniv Yedid-Levi. All rights reserved. Short sections of text, not to exceed two paragraphs, may be quoted without explicit permission provided that full credit, including $\odot$ notice, is given to the source. 


\title{
How Exporters Grow
}

Doireann Fitzgerald, Stefanie Haller, and Yaniv Yedid-Levi

NBER Working Paper No. 21935

January 2016, Revised December 2019

JEL No. E2,F1,L1

\begin{abstract}
$\underline{\text { ABSTRACT }}$
We show that in successful episodes of export market entry, there are statistically and economically significant post-entry dynamics of quantities, but no post-entry dynamics of markups. This suggests that shifts in demand play an important role in successful entry, but that firms do not use dynamic manipulation of markups as an instrument to shift demand. We structurally estimate two competing models of customer base accumulation to match these moments. In the first model, firms use marketing and advertising to acquire new customers and thereby shift demand and increase sales. In the second, they use temporarily low markups to do so. The marketing and advertising model fits the quantity and markup moments well, and implies that successful entry is associated with high selling expenses. The second model cannot simultaneously fit quantity and markup moments, even with a counterfactually high price elasticity of demand and trade elasticity. We conclude that successful market entry is more likely to be associated with high selling expenses than low markups.

Doireann Fitzgerald

Federal Reserve Bank of Minneapolis

90 Hennepin Ave

Minneapolis, MN 55401

doireann.fitzgerald@gmail.com

Stefanie Haller

University College Dublin

School of Economics

Belfield

Dublin 4

Ireland

stefanie.haller@ucd.ie

\author{
Yaniv Yedid-Levi \\ University of British Columbia \\ yaniv.yl1@gmail.com
}




\section{Introduction}

Recent research makes customer base central to the analysis of firm dynamics, business cycles, and international trade. ${ }^{1}$ Although much has been learned, there is as yet no consensus on how best to model the mechanisms through which firms' demand and customer base grow after entry into a market. There are two main competing models of customer base accumulation in the literature: (1) firms acquire customer base through engaging in nonprice activities such as marketing and advertising (we refer to this as the "marketing and advertising model"), and (2) customer base is a function of past sales, so firms expand in a market by first charging low markups to shift out demand, then gradually increasing markups as customer base rises (we refer to this as the "customer markets model"). We use customs data for Ireland for the period 1996-2009, and a combination of reduced form and structural estimation, to distinguish between these two competing models, finding that the data is more consistent with the marketing and advertising model than the customer markets model.

Though we make use of customs data, our work has implications beyond the literature on exporter dynamics. In particular, we highlight the potential importance of selling expenses for firms which are successfully expanding into to new markets. This has several implications. If the inputs devoted to acquiring new customers cannot be separated from those used in production, productivity may be systematically mismeasured for growing versus stagnant firms. The importance of selling expenses, and hence mismeasurement, could also vary over time. The years since 2001 have seen a simultaneous wave of market integration, and a slowdown in measured productivity. By highlighting the importance of selling expenses in successful entry, we raise the possibility that these two trends could be linked. Consistent with this story, De Loecker et al. (2019) and Traina (2018) find that Selling, General and Administrative expenses account for a rising share of total costs in Compustat firms since the 1980s. These authors disagree on whether these expenses are properly part of fixed cost or marginal cost, but the trend in these costs is not in dispute.

It is possible to distinguish between these two competing models of customer base accumulation using only market-level data on quantities and prices following entry. In the marketing and advertising model, growth in market share is possible without any dynamics in prices or markups. In the customer markets model, firms build market share by charging

\footnotetext{
${ }^{1}$ See, among others, Arkolakis (2016), Drozd and Nosal (2012a,b) Eaton et al. (2011), Eaton et al. (2014), Foster et al. (2008, 2016), Gilchrist et al. (2017), Gourio and Rudanko (2014), Ravn et al. (2006), Ruhl and Willis (2017).
} 
initially low markups, which then increase with tenure. The ability to exploit quantity and price data is useful, because data on selling expenses, especially data on selling expenses at the level of the individual market, is hard to come by.

Customs data on exports matched to firms is very well suited to this exercise, because for each exporting firm, and for each 8-digit product a firm exports, we observe quantity and price (unit value) for possibly multiple naturally segmented markets (i.e. countries). For markets which a firm enters during the sample, we observe the timing of entry, and hence tenure in the market. Although mature exporters account for the majority of export sales, even for these firms, there is a lot of entry and exit at the level of the firm-market and firm-product-market.

Our reduced form empirical strategy is guided by a formal analysis of the predictions of our two competing models, under the assumption that there are three important dimensions of heterogeneity in the data: marginal cost, market size, and firm-product-market-specific idiosyncratic demand. In the first step of our empirical strategy, we isolate variation in markups, and variation in quantities across markets that cannot be explained by variation in marginal cost, by comparing log quantities and prices across markets within a firm-productyear using firm-product-year fixed effects. In the second step, to control for all demand-side factors that are common across firms, we compare across firms within a product-market-year using product-market-year fixed effects.

Next, in order to separate dynamics from selection on unobserved heterogeneity, we must control for firm-product-market-specific idiosyncratic demand. In addition, our models tell us that the permanent components of marginal cost, market size, and idiosyncratic demand affect not just the levels of quantities and markups, but also their growth. So our third step is to exploit predictions of the models to construct proxies for these three dimensions of unobserved heterogeneity. Our proxy for marginal cost is the number of markets a firm ever exports to over its time in the sample. Our proxy for market size is the number of firms that ever export to a market over the sample period. Our proxy for idiosyncratic demand is the duration of an export episode (i.e. the total length of time from entry to exit). ${ }^{2}$

Finally we regress residualized quantities and prices on a rich set of interactions between tenure, duration, and our marginal cost and market size proxies. We then evaluate the fitted values of all possible duration-tenure combinations at fixed values of the marginal cost and market size proxies. This gives us the dynamic evolution of quantities and markups post-entry for different levels of idiosyncratic demand.

\footnotetext{
${ }^{2}$ This follows Abraham and Farber (1987), who use duration to proxy for unobserved heterogeneity in the quality of worker-firm matches in order to obtain an unbiased estimate of returns to job tenure.
} 
We find that there are statistically and economically significant post-entry dynamics of quantities which vary with the duration of an export episode: In export episodes which last at least 7 years, quantities grow four-fold between the first year and the fifth year. Markups, in contrast, are flat. Quantities on entry are substantially larger in ultimately longlived export episodes than in short-lived export episodes. However there is no statistically significant relationship between markups on entry and survival. We perform a comprehensive set of robustness checks to confirm these facts. They hold across a range of manufacturing industries, across different export markets, and across domestic- and foreign-owned firms.

This joint behavior of quantities and markups confirms that shifts in demand play an important role in exporter growth. It implies that, rather than temporarily depressing markups to acquire new customers, it is more likely that firms use non-price actions such as marketing and advertising to shift demand. To test this hypothesis more formally, we use a moment-based approach to structurally estimate the two competing models of customer base accumulation to match the post-entry behavior of quantities and markups, as well the exit hazard..$^{3}$

The marketing and advertising model fits the target moments well. It matches the relationship between quantities on entry and survival in a market. It matches the growth of quantities in successful export spells. By construction, it matches the behavior of markups. It also matches the downard slope of the exit hazard. In this model, the trade elasticity (longrun elasticity of exports with respect to e.g. tariffs) is not pinned down by the quantity and markup moments, because with flat markups, all changes in quantity are driven by shifts in demand rather than movements along a demand curve. But combining our estimates of model parameters with price elasticities of demand in the range 1.5 to 4 , we obtain trade elasticities in the range 3 to 8 , consistent with what is found in the literature.

In contrast, the customer markets model has more difficulty matching the moments. A key parameter in this model is the price elasticity of demand, which governs the size of the change in the markup necessary to generate a given shift in future demand. Because there is substantial growth in quantities post-entry, but no growth in markups, our estimate of the price elasticity of demand in this model is counterfactually high. It implies a trade elasticity of over 100, which is well outside the range of values used in the literature. We take this extreme parameter estimate as an indication that the markup channel is unlikely to play an important role in customer base accumulation. Our structural estimates thus confirm the findings of our reduced form analysis, and strongly suggest that firms use non-price activities

\footnotetext{
${ }^{3}$ In a robustness check we also estimate a model where post-entry dynamics are due to learning about idiosyncratic demand. The fit of this model is very poor.
} 
such as marketing and advertising rather than markups to accumulate customer base and increase market share.

An advantage to structurally estimating the marketing and advertising model is that we can quantify selling expenses as a fraction of gross margins (revenue net of total marginal cost). They are highest on entry, and decline with tenure. If we combine our parameter estimates with an assumption about the price elasticity of demand, we can recover selling expenses as a share of revenue. With a price elasticity of demand of 3, we find that selling expenses account for $15 \%$ of revenue in the latter years of export spells which last 7 or more years. These numbers are within the range of what the empirical literature on this issue finds. $^{4}$

Our contribution is related to a number of other papers that investigate post-entry price dynamics using manufacturing census and customs data. ${ }^{5}$ When using specifications that are similar to ours, this literature estimates price behavior that lies within (or very close to) our standard error bands. In contrast to other papers in this area, we use a comprehensive set of quantity, price and exit moments to structurally estimate competing models of customer base accumulation, and to ask which one the data favors. In doing so, we contribute to the literature on firm dynamics, to the literature on business cycles, and to the literature on international trade, as we discuss in detail in the conclusion.

The paper is organized as follows. In the next section, we lay out our two competing models of customer base accumulation. In the third section we describe how we construct reduced form moments of the data that can be used to distinguish between the two models. In the fourth section, we describe our data. In the fifth section, we describe our reduced form results. In the sixth section we describe how we structurally estimate the two competing models to match these moments and report the results of this exercise. The final section concludes by discussing some implications of our findings for the literature.

\section{Two models of customer base accumulation}

Our marketing and advertising model is a dynamic generalization of Arkolakis (2010). His is a static model where firms can shift their current demand (the price elasticity of demand is

\footnotetext{
${ }^{4}$ Using Compustat data from the U.S. for 1971-2006, Gourio and Rudanko (2014) find that firms for which "Selling, General, and Administrative Expenses" (SG\&A) are above the industry median have an average share of SG\&A in sales of $27 \%$, while firms for which SG\&A are below the industry median have an average share of SG\&A in sales of $17 \%$.

${ }^{5}$ This includes Foster et al. (2008) who use plant census data for the US, and Bastos et al. (2018), Berman et al. (2019) and Piveteau (2019) who use customs data for Portugal and France.
} 
unaffected) by making within-period marketing and advertising expenditures, with decreasing returns. ${ }^{6}$ We generalize this model by assuming that expenditures on marketing increase customer base, which need not depreciate fully between one period and the next. Customer base in turn shifts demand. Expenditures on marketing and advertising thus play the role of a market-specific investment. If there are adjustment costs, customer base need not jump straight to steady state customer base on entry. Our setup is also related to Drozd and Nosal (2012a) who build a two-country dynamic general equilibrium model with firms which accumulate customer base through marketing expenditures.

Our second model closely follows Foster, Haltiwanger and Syverson (2016), who assume that customer base is a function of past sales rather than marketing and advertising expenditures. Their model is related to a long tradition of "customer markets" models in macroeconomics (e.g. Bils (1989), Ravn et al (2006)). In this model, if a firm's customer base is below its steady state level, it has an incentive to set a below-steady-state markup, giving up some profit today in return for higher customer base and higher profits in the future. As customer base converges to its steady state level, the incentive to distort markups diminishes. Hence, the optimal price increases as customer base grows towards its steady state level. The price elasticity of demand is a key parameter governing this tradeoff: the more elastic is demand, the smaller the reduction in price necessary to generate a given shift in demand.

We build a parsimonious model of export entry and exit in mutiple segmented markets within which to place the two models of customer base accumulation. While our models have implications for firm dynamics (i.e. aggregating across all markets served by the firm), we do not explore them, focusing instead on the process of selection and post-entry dynamics at the market level. We start by describing the common elements of the two models.

Firms are indexed by $i$, and markets are indexed by $k$. Markets are segmented, so the firm is able to price discriminate. The only channel through which a firm's decisions across different markets are linked is through its common exogenous marginal cost of production, $C_{t}^{i}{ }^{7}$ In each export market $k$, the firm faces stochastic sunk $\left(S_{t}^{i k}\right)$ and fixed $\left(F_{t}^{i k}\right)$ costs of participation. These costs are iid. Sunk costs lead to selection on entry, while fixed costs lead to selection on exit.

\footnotetext{
${ }^{6}$ Arkolakis's model is in the tradition of informative advertising.

${ }^{7}$ In Appendix A, we lay out a model augmented with firm-level heterogeneity in quality as well as cost.
} 
Conditional on participation, demand is isoelastic:

$$
Q_{t}^{i k}=Q_{t}^{k}\left(\frac{P_{t}^{i k}}{P_{t}^{k}}\right)^{-\theta}\left(D_{t}^{i k}\right)^{\alpha} \exp \left(\nu_{t}^{i k}\right)
$$

Here, $Q_{t}^{k}$ is aggregate demand in market $k$ and $P_{t}^{k}$ is an index of competitors' prices. Going forward, we write $Y_{t}^{k}=Q_{t}^{k}\left(P_{t}^{k}\right)^{\theta}$, and refer to $Y_{t}^{k}$ as market size. ${ }^{8}$ Exogeneity of market size relies on monopolistic competition. Demand also depends on the exogenous idiosyncratic demand shifter $\nu_{t}^{i k}$. The firm affects the quantity sold by choosing the price, $P_{t}^{i k}$, and by taking actions which affect $D_{t}^{i k}$, i.e. customer base, which shifts demand conditional on price. If $\alpha \in(0,1)$, demand is increasing in customer base, but at a diminishing rate. If $\alpha=0$, demand does not depend on customer base.

There are three sources of potentially persistent heterogeneity in the model: $C_{t}^{i}$ at the firm-level, $Y_{t}^{k}$ at the market level, and $\nu_{t}^{i k}$ at the firm-market level. We do not take a stand on the statistical processes for $C_{t}^{i}$ and $Y_{t}^{k}$, other than to assume they have a persistent component. We assume that conditional on entry, idiosyncratic demand is the sum of a "permanent" component $\left(\bar{\nu}_{t}^{i k}\right)$ and a transitory component $\left(\tilde{\nu}_{t}^{i k}\right): \nu_{t}^{i k}=\bar{\nu}_{t}^{i k}+\tilde{\nu}_{t}^{i k}$. The permanent component remains fixed within an export spell (an episode of continuous participation). On exit, the firm loses its draw of $\bar{\nu}_{t}^{i k}$, and receives a new draw of $\bar{\nu}_{t}^{i k}$ in every subsequent period of non-participation.

At this point, the two different models of demand and customer base diverge, and we describe them separately.

\subsection{Marketing and advertising}

Let $X_{t}^{i k}=\{0,1\}$ be an indicator for participation. Firms entering market $k$ start with customer base $\underline{D}^{k}$. Customer base in market $k$ accumulates according to:

$$
D_{t}^{i k}=\left(1-X_{t-1}^{i k}\right) \underline{D}^{k}+X_{t-1}^{i k}\left((1-\delta) D_{t-1}^{i k}+A_{t-1}^{i k}\right)
$$

$A_{t-1}^{i k}$ is the increment to customer base at date $t$ due to marketing and advertising at date $t-1 .^{9}$ The depreciation rate of past customer base conditional on continued participation

\footnotetext{
${ }^{8}$ In Appendix A we show that iceberg trade costs and tariffs enter the firm's problem in the same way as market size.

${ }^{9} \mathrm{We}$ adopt this timing to facilitate comparisons between this model and the customer markets model. The model works very similarly when investment in marketing and advertising affects customer base within the period.
} 
is $\delta$. Customer base fully depreciates on exit.

The cost of marketing and advertising is given by $c\left(D_{t}^{i k}, A_{t}^{i k}\right)$, where $c(\cdot, 0)=0$, and $c(\cdot, \cdot)$ is differentiable in both arguments, with $c_{A}>0, c_{A A} \geq 0$ and $c_{D} \leq 0$. Since customer base is intangible, it is natural to assume irreversibility (i.e. $A_{t}^{i k} \geq 0$ ).

In this model, current participation $\left(X_{t}^{i k}\right)$ and investment $\left(A_{t}^{i k}\right)$, affect future as well as current profits. The choice of price affects only current profit, and the optimal price is:

$$
P_{t}^{i k}=\frac{\theta}{\theta-1} C_{t}^{i}
$$

Let $Z_{t}^{i k}=\left\{Y_{t}^{k}, C_{t}^{i}, S_{t}^{i k}, F_{t}^{i k}, \nu_{t}^{i k}\right\}$. Profit conditional on participation at $t$ is:

$$
\begin{gathered}
\pi\left(X_{t-1}^{i k}, D_{t}^{i k}, Z_{t}^{i k}, A_{t}^{i k}\right)=\frac{(\theta-1)^{\theta-1}}{\theta^{\theta}} Y_{t}^{k}\left(C_{t}^{i}\right)^{1-\theta}\left(D_{t}^{i k}\right)^{\alpha} \exp \left(\nu_{t}^{i k}\right) \\
-c\left(D_{t}^{i k}, A_{t}^{i k}\right)-F_{t}^{i k}-\left(1-X_{t-1}^{i k}\right) S_{t}^{i k}
\end{gathered}
$$

The Bellman equation for the firm's problem is:

$V\left(X_{t-1}^{i k}, D_{t}^{i k}, Z_{t}^{i k}\right)=\max _{X_{t}^{i k} \in\{0,1\}, A_{t}^{i k}>0}\left\{X_{t}^{i k} \pi\left(X_{t-1}^{i k}, D_{t}^{i k}, Z_{t}^{i k}, A_{t}^{i k}\right)+\beta \mathbb{E}\left\{V\left(X_{t}^{i k}, D_{t+1}^{i k}, Z_{t+1}^{i k}\right) \mid Z_{t}^{i k}\right\}\right\}$

subject to the evolution of customer base. After describing the customer markets model, we characterize some important properties of the solution to this problem.

\subsection{Customer markets}

Firms entering market $k$ start with customer base $\underline{D}^{k}$. Customer base in market $k$ accumulates according to: ${ }^{10}$

$$
D_{t}^{i k}=\left(1-X_{t-1}^{i k}\right) \underline{D}^{k}+X_{t-1}^{i k}\left((1-\delta) D_{t-1}^{i k}+P_{t-1}^{i k} Q_{t-1}^{i k}\right)
$$

The depreciation rate of customer base conditional on continued participation is $\delta$. Customer base fully depreciates on exit.

In this model, current participation and prices affect future as well as current profits. Let $Z_{t}^{i k}=\left\{Y_{t}^{k}, C_{t}^{i}, S_{t}^{i k}, F_{t}^{i k}, \nu_{t}^{i k}\right\}$ as above. Profit conditional on participation is:

$$
\pi\left(X_{t-1}^{i k}, D_{t}^{i k}, Z_{t}^{i k}, P_{t}^{i k}\right)=\left(P_{t}^{i k}-C_{t}^{i}\right) Y_{t}^{k}\left(P_{t}^{i k}\right)^{-\theta}\left(D_{t}^{i k}\right)^{\alpha} \exp \left(\nu_{t}^{i k}\right)
$$

\footnotetext{
${ }^{10}$ To facilitate comparisons between this model and the customer markets model, we depart from Foster et al. (2016) by having depreciation apply only to past customer base, and not to past sales.
} 


$$
-F_{t}^{i k}-\left(1-X_{t-1}^{i k}\right) S_{t}^{i k}
$$

The Bellman equation for the firm's problem is:

$V\left(X_{t-1}^{i k}, D_{t}^{i k}, Z_{t}^{i k}\right)=\max _{X_{t}^{i k} \in\{0,1\}, P_{t}^{i k}>0}\left\{X_{t}^{i k} \pi\left(X_{t-1}^{i k}, D_{t}^{i k}, Z_{t}^{i k}, P_{t}^{i k}\right)+\beta \mathbb{E}\left\{V\left(X_{t}^{i k}, D_{t+1}^{i k}, Z_{t+1}^{i k}\right) \mid Z_{t}^{i k}\right\}\right\}$

subject to the accumulation of customer base.

\subsection{Model predictions}

To simplify, we assume marginal cost is constant for each firm $\left(C_{t}^{i}=C^{i}\right)$, market size is constant for each market $\left(Y_{t}^{k}=Y^{k}\right)$, and there is no transitory component of idiosyncratic demand, i.e. $\nu_{t}^{i k}=\bar{\nu}^{i k}$ (we drop the $t$ subscript to indicate that idiosyncratic demand is fixed).

The following proposition about the nature of selection holds for both models, and turns out to be very useful for our empirical strategy:

Proposition 1. Fix $C^{i}, Y^{k}$, and $D_{t}^{i k}$. Then the probability of survival is increasing in $\bar{\nu}^{i k}$.

Proof See Appendix B.

The intuition is very straightforward. On exit, the firm loses its current draw of the permanent component of idiosyncratic demand. The value of exit is therefore independent of this draw, while the value of continued participation is increasing in this draw. Hence, the probability that the firm will choose to exit is decreasing in its current draw of the permanent component of idiosyncratic demand. This implies that appropriate functions of the survival probability will also be monotonic in $\bar{\nu}^{i k}$. We conjecture that the probability of survival is also decreasing in costs and increasing in market size, though we have not been able to prove it formally. ${ }^{11}$

If in addition, we assume there is no endogenous exit, that the adjustment cost function in the marketing and advertising model takes the form $c(D, A)=A+\phi\left(A^{2} / D\right)$ and that the resulting value functions are differentiable and concave, we can prove the following propositions about the post-entry behavior of quantities in both models: ${ }^{12}$

Proposition 2. Quantity on entry is decreasing in $C^{i}$, and increasing in $Y^{k}$ and $\bar{\nu}^{i k}$.

\footnotetext{
${ }^{11}$ This is tricky to prove because the value of participation and the value of staying out of the market are both decreasing in cost and increasing in market size.

${ }^{12}$ This is the functional form we use in the structural estimation.
} 
Proof See Appendix B.

Proposition 3. Growth in quantity on entry (i.e. growth between the first and second periods of participation) depends on $C^{i}, Y^{k}$ and $\bar{\nu}^{i k}$.

Proof See Appendix B.

In the marketing and advertising model, we can additionally prove that if customer base on entry is below steady state customer base, then quantity converges to steady state quantity from below, and quantity growth on entry is decreasing in $C^{i}$, and increasing in $Y^{k}$ and $\bar{\nu}^{i k}$.

Meanwhile, the post-entry behavior of markups differs across the two models:

Proposition 4. In the marketing and advertising model, the markup is independent of $C^{i}$, $Y^{k}$ and $\bar{\nu}^{i k}$.

Proof See Appendix B.

Proposition 5. In the customer markets model, the markup on entry is increasing in $C^{i}$ and decreasing in $Y^{k}$ and $\bar{\nu}^{i k}$.

Proof See Appendix B.

Proposition 6. In the customer markets model, if customer base on entry is below steady state customer base, then (a) the markup converges to the steady state markup from below, and (b) growth in the markup on entry (i.e. growth between the first and second periods of participation) is decreasing in $C^{i}$, and increasing in $Y^{k}$ and $\bar{\nu}^{i k}$.

Proof See Appendix B.

The intuition for Proposition 6 is that markup distortions are an investment in customer base. Steady state customer base is decreasing in marginal cost and increasing in market size and idiosyncratic demand. Holding fixed customer base on entry (as we do in the model), the greater is steady state customer base, the greater the incentive to invest.

We conjecture that the behavior we characterize in Propositions 2-6 carries over to the case of endogenous exit.

\section{$3 \quad$ Reduced form empirical strategy}

The goal of our empirical strategy is twofold. We want to confirm that customer base accumulation is an important source of post-entry dynamics in our data. We also want to 
see whether post-entry dynamics in quantities and markups can help distinguish between the two potential models of accumulation. We tie our strategy tightly to these models, as the moments we construct will also be used as inputs into our simulated method of moments estimation in Section 6. We first give an overview of our strategy and then describe the implementation in detail.

\section{$3.1 \quad$ Overview}

Our first step in understanding customer base accumulation is to isolate variation in markups, and variation in quantities across markets that cannot be explained by variation in marginal cost. The fact that in our customs data we observe the same firm selling the same product in multiple different markets makes this easy. Under the assumptions we make in Section 2 of common marginal cost across markets, and isoelastic demand, we can use a fixed effects strategy (i.e. differencing log quantities and log prices across markets within a firm-productyear) to do this (note that the relationship between prices, markups and marginal cost is log-linear by definition).

Our second step in understanding customer base accumulation is to control for all demandside factors that are common across firms. The fact that we observe multiple firms selling the same product in the same market makes this easy too. Under the assumptions we make in Section 2 of common market size across firms, and isoelastic demand, we can again use a fixed effects strategy (i.e. differencing log quantities and log prices across all firms within a product-market-year).

However, identifying dynamics due to customer base accumulation is not as straightforward as regressing residualized log quantities and log prices on indicators for tenure (i.e. number of years a firm-product has continually participated a market). There are two reasons for this.

First, Proposition 1 tells us that there is selection on persistent unobserved heterogeneity in idiosyncratic demand. This implies that firm-product-markets which reach high tenure have higher idiosyncratic demand on average firm-product-markets which exit early. We therefore need to control for the persistent component of idiosyncratic demand to obtain an unbiased estimate of the relationship between quantities, markups, and tenure.

Second, Propositions 2-6 tell us that the post-entry dynamics of quantities and markups depend on marginal cost, market size, and idiosyncratic demand. The intuition is that firms with low marginal cost selling in markets where demand is high have a greater incentive to invest in customer base than firms with high marginal cost selling in markets with low 
demand. So we also need to allow the growth rates of quantities and markups to vary with these three sources of persistent unobserved heterogeneity. Note that Propositions 4-6 also tell us that the comparative statics of the relationship between markups and tenure with respect to marginal cost, market size, and idiosyncratic demand differ across models. Estimating these comparative statics therefore helps us to distinguish between the two models of customer base accumulation.

So in a third step, we construct proxies for the permanent components of marginal cost, market size, and idiosyncratic demand so that (a) we can control for the level effect of idiosyncratic demand, and (b) we can allow dynamics to depend on all three types of unobserved heterogeneity.

We construct our proxy for idiosyncratic demand by exploiting Proposition 1. It states that, conditional on marginal cost, market size, and customer base, the probability of survival is increasing in the permanent component of idiosyncratic demand. Now define the duration of an export episode as the length of time between entry and exit, a variable which is fixed for a given export episode. Note that duration $\left(L_{t}^{i k}\right)$ conditional on entry at date $t$ (i.e. $\left.X_{t}^{i k}=1, X_{t-1}^{i k}=0\right)$ is a forward-looking function of survival:

$$
L_{t}^{i k}=\sum_{s^{\prime}=1}^{\infty} \prod_{s=1}^{s^{\prime}} X_{t+s}^{i k}
$$

This implies that conditional on marginal cost, market size, and customer base, duration is increasing in the permanent component of idiosyncratic demand. So, as long as we control for these variables (we explain below how we do so) duration can be used to proxy for the permanent component of idiosyncratic demand. ${ }^{13}$

There are several potential proxies for the permanent component of marginal cost, especially since our customs data is matched to the census of manufacturing firms. But we follow a logic similar to that for idiosyncratic demand, and use the number of distinct markets a firm exports to over the entire sample period as our (time-invariant) proxy. This is motivated by the fact that in static models with fixed costs of export participation, there is a decreasing relationship between the number of markets a firm exports to and its marginal cost. ${ }^{14}$ We examine below how variation in this proxy correlates with other potential measures.

We adopt a similar strategy to construct a proxy for the permanent component of market size. We use the number of distinct firms which export to a market over the sample period

\footnotetext{
${ }^{13}$ As noted in the introduction, this follows Abraham and Farber (1987).

${ }^{14}$ We conjecture that this property extends to our dynamic models of export participation.
} 
as our proxy for the size of that market. Again, this is motivated by the fact that in static models with fixed costs of export participation, there is an increasing relationship between the number of firms that export to a market, and market size. Relative to alternative proxies such as GDP and bilateral distance, this proxy has the advantage of parsimony, in that it collapses multiple dimensions of heterogeneity (e.g. size, distance) into a single index. We examine below how variation in this proxy correlates with these other potential measures.

Note that we construct our proxy for marginal cost at the firm level, and our proxy for market size at the market level, while our proxy for idiosyncratic demand varies at the firm-product-market level.

We then generate a full set of interactions between indicator variables for duration and indicator variables for tenure. Our baseline empirical specification regresses log quantities and log prices on firm-product-year and market-product-year fixed effects, and on a vector of indicator variables for duration indicated with a vector of indicator variables for tenure. This vector of duration $\times$ tenure is further interacted with our proxies for marginal cost and market size. This allows both the levels and the growth rates of quantities and markups to depend on all three dimensions of unobserved heterogeneity.

We present our results in the form of fitted values of all possible duration-tenure combinations evaluated at fixed values of the proxies for costs and market size. Because we control for tenure and for the effect of marginal cost and market size on both levels and growth rates of quantities and markups, the trajectories for spells of increasing duration give us the dynamic evolution of quantities and markups at increasing levels of idiosyncratic demand. Focusing on comparative statics with respect to this single dimension of heterogeneity makes our reduced form results easier to interpret. In addition, it allows us to hold costs and market size fixed when estimating our structural model.

Finally, we verify that conditional on firm- and market-specific heterogeneity, the hazard of exit is downward-sloping, consistent with selection on idiosyncratic demand, as in Proposition 1. This confirms that we need to control for the permanent component of idiosyncratic demand in our analysis, as well as justifying our duration-based approach to doing so. In the structural estimation, we use the fitted value of the exit hazard, together with comparative statics of quantities and markups with respect to duration to discipline the underlying process for idiosyncratic demand. ${ }^{15}$

\footnotetext{
${ }^{15}$ There is measurement error associated with the use of proxies for marginal cost, market size, and idiosyncratic demand. We explicitly model the error in the proxy for idiosyncratic demand in the structural estimation.
} 


\subsection{Measurement}

Our baseline data is a panel of firms, products and markets (countries), observed at an annual frequency. We observe quantities and values, and hence unit values, or prices, at the firm-product-market-year level. We define an export spell as a continuous episode of market participation, i.e. an episode in which there are positive exports in every consecutive year. Spell entry is observed if we see a year with non-participation prior to a year with participation. Spell entry is censored if we see exports in the first year of the sample. ${ }^{16}$ Similarly, spell exit is observed if we see a year of participation followed by a year of nonparticipation, but censored if we see exports in the last year of the sample. If we observe zero exports for one or more years after some positive exports, any reentry is counted as part of a distinct export spell. ${ }^{17}$

We define export tenure as follows. We set tenure equal to 1 in the first year a firm exports a given product to a given market after not exporting in the previous period. Tenure is incremented by 1 in each subsequent year of continuous participation. If the firm-product exits a market for some period, tenure is reset to 1 in the first subsequent year of participation. Note that we do not observe tenure if entry is censored.

We define duration as tenure on exit. Duration is observed only if an export spell is neither left- nor right-censored. However for right-censored spells, we know that duration is at least as great as duration at the end of the sample. By top-coding duration at some number, we can make use of this information. As a baseline, we topcode both tenure and duration at 7 years. ${ }^{18}$

At this point it is worth mentioning the potential impact of partial-year effects. The fact that firms may enter or exit markets part-way through a calendar year can affect the observed relationship between quantities, prices, exit, and tenure. Notice that our nonparametric approach to controlling for duration and tenure allows for any nonlinearities around entry and exit induced by this issue. In interpreting our moments, we are careful to take part-year effects into account, and we explicitly incorporate them into our structural models. $^{19}$

\footnotetext{
${ }^{16}$ Our sample starts in 1996, but because of issues with the match between customs data and firms in that year, we also consider spell entry to be censored if it takes place in 1997.

${ }^{17}$ In our baseline analysis we treat these "reentry" spells the same as "first entry" spells.

${ }^{18}$ Using our full panel of customs data, which lasts for 19 years, we show that our key results are robust to top-coding at levels up to 10 years.

${ }^{19}$ Some authors who have access to higher-frequency data correct for this issue by dating the beginning of an export spell e.g. from its first month, and aggregating to an annual frequency starting each "year" in the entry month. This option is not open to us, and this would in any case invalidate the use of calendar year fixed effects to control for the first order effects of marginal cost and market size.
} 
As mentioned above, we use the number of markets a firm ever exports to over the full sample period to proxy for the permanent component of firm-specific marginal cost, while we use the number of firms ever exporting to a particular market over the full sample period to proxy for the permanent component of market size. We conduct our analysis of quantities and prices at the firm-product-market level, but we work with these proxies at the firm and market level.

\subsection{Implementation}

Let $w_{t}^{i j k}$ denote $\log$ quantity, or $\log$ price. Let $c_{t}^{i j}$ be a a set of firm-product-year fixed effects. Let $d_{t}^{j k}$ be a set of product-market-year fixed effects. Let $\mathbf{a}_{t}^{i j k}$ be a vector of indicator variables for firm $i$ 's tenure (in years) in market $k$ with product $j$. Let $\mathbf{l}_{t}^{i j k}$ be a vector of indicators for the duration (in years) of the relevant spell. This indicator does not vary within a spell, but is indexed by $t$ to capture the fact that we may observe multiple export spells of different length for firm $i$, product $j$, and market $k$ over the period of our panel. Let cens $^{i j k}$ be a vector of indicators for spells that are left-censored (cens $s_{l}^{i j k}$ ), and for spells that are right-censored but not left-censored given the top-code of duration $\left(\right.$ cen $\left._{r}^{i j k}\right)$. Then let:

$$
\mathbf{s}_{t}^{i j k}=\left[\begin{array}{c}
\mathbf{l}_{t}^{i j k} \otimes \mathbf{a}_{t}^{i j k} \\
\mathbf{c e n s}^{i j k}
\end{array}\right]
$$

where the symbol $\otimes$ indicates the Kronecker product. We do not observe tenures of greater than $l$ for a spell that lasts $l$ years, so the redundant interactions are dropped. We code $\mathbf{s}_{t}^{i j k}$ such that log quantity is normalized to 0 for 1 -year export spells. Let $m^{i}$ and $f^{k}$ be the number of markets per firm and the number of firms per market as described above.

Our baseline estimating equation is then:

$$
w_{t}^{i j k}=c_{t}^{i j}+d_{t}^{j k}+\boldsymbol{\beta}^{\prime}\left(\mathbf{s}_{t}^{i j k} \otimes\left(\begin{array}{c}
1 \\
m^{i} \\
f^{j}
\end{array}\right)\right)+\epsilon_{t}^{i j k}
$$

We include all observations with positive exports in estimating this equation. Because $\mathbf{s}_{t}^{i j k}$ includes all possible combinations of tenure and duration, our specification is fully nonparametric with respect to these variables, and semi-parametric with respect to $m^{i}$ and $f^{k}$. We can then use the estimated coefficients $\boldsymbol{\beta}$ to obtain $E\left(w_{t}^{i j k} \mid a, l, m^{i}, f^{k}, c_{t}^{i j}, d_{t}^{j k}\right)-$ $E\left(w_{t}^{i j k} \mid 1,1, m^{i}, f^{k}, c_{t}^{i j}, d_{t}^{j k}\right)$ for all possible combinations of tenure $a$ and duration $l$, condi- 
tional on fixed values of $m^{i}$ and $f^{k}$. This allows us to obtain dynamics for fixed idiosyncratic demand, and construct comparative statics of levels and dynamics with respect to idiosyncratic demand.

To characterize the conditional exit hazard, we estimate the following linear probability model:

$$
\operatorname{Pr}\left[X_{t+1}^{i j k}=0 \mid X_{t}^{i j k}=1\right]=c_{t}^{i j}+d_{t}^{j k}+\boldsymbol{\beta}^{\prime}\left(\left(\begin{array}{c}
\mathbf{a}_{t}^{i j k} \\
\operatorname{cens}_{l}^{i j k}
\end{array}\right) \otimes\left(\begin{array}{c}
1 \\
m^{i} \\
f^{k}
\end{array}\right)\right)+\epsilon_{t}^{i j k}
$$

We include all observations where exit is not censored by the end of the sample. The terms $c_{t}^{i j}$, $d_{t}^{j k}, \mathbf{a}_{t}^{i j k}$ and $c e n s_{l}^{i j k}$ are defined as above. We code $\mathbf{a}_{t}^{i j k}$ and $c e n s_{l}^{i j k}$ such that the exit hazard is normalized to zero for for the first year of an export spell. Based on our estimates of this expression, we can trace out $\operatorname{Pr}\left[X_{t+1}^{i j k}=0 \mid a, m^{i}, f^{k}, c_{t}^{i j}, d_{t}^{j k}\right]-\operatorname{Pr}\left[X_{t+1}^{i j k}=0 \mid 1, m^{i}, f^{k}, c_{t}^{i j}, d_{t}^{j k}\right]$ for all possible values of tenure $a$, conditional on fixed values of $m^{i}$ and $f^{k}$.

Because they are useful as target moments in the structural estimation, we also regress entry rates and one-year exit rates on $m^{i}$ and $f^{k}$. For entry, we estimate the following linear probability model:

$$
\operatorname{Pr}\left[X_{t+1}^{i j k}=1 \mid X_{t}^{i j k}=0\right]=\boldsymbol{\beta}^{\prime}\left(\begin{array}{c}
1 \\
m^{i} \\
f^{k}
\end{array}\right)+\epsilon_{t}^{i j k}
$$

In estimating this equation, we include only firm-product and market-product combinations for which at least one positive export is observed. This allows us to characterize $\operatorname{Pr}\left[X_{t+1}^{i j k}=1 \mid X_{t}^{i j k}=0, m^{i}, f^{k}\right]$. For one-year exit, we estimate the following linear probability model:

$$
\operatorname{Pr}\left[X_{t+1}^{i j k}=0 \mid X_{t}^{i j k}=1, X_{t-1}^{i j k}=0, a_{t}^{i j k}=1\right]=\boldsymbol{\beta}^{\prime}\left(\begin{array}{c}
1 \\
m^{i} \\
f^{k}
\end{array}\right)+\epsilon_{t}^{i j k}
$$

This allows us to characterize $\operatorname{Pr}\left[X_{t+1}^{i j k}=0 \mid 1, m^{i}, f^{k}\right]$, and hence calculate entry and 1-year exit rates conditional on fixed values of $m^{i}$ and $f^{k}$.

In addition, we estimate (8) at the firm-market level, using log revenue and log number of products as the dependent variables. We also estimate (9), (10) and (11) at the firm-market level. In the case of entry at the firm-market level, we include all firms (including those 
which never export), and all markets to which at least one firm in the data exported over our sample period. In all cases, we construct the fitted values conditional on the same fixed values of $m^{i}$ and $f^{k}$.

\section{Data description}

We make use of two sources of confidential micro data made available to us by the Central Statistics Office (CSO) in Ireland: the Irish Census of Industrial Production (CIP) and Irish customs records. The data are described in detail in Appendix D.

\subsection{Census of Industrial Production}

The CIP is an annual census of manufacturing, mining, and utilities. Firms with three or more persons engaged are required to file returns. ${ }^{20}$ We make use of data for the years 1996-2009 and for NACE Revision 1.1 sectors 10-40 (manufacturing, mining, and utilities). Of the variables collected in the CIP, those we make use of in this paper are total revenue, employment, and country of ownership.

In constructing our sample for analysis, we drop firms with a zero value for total revenue or zero employees in more than half of their years in the sample. We perform some recoding of firm identifiers to maintain the panel dimension of the data, for example, in cases in which ownership changes.

\subsection{Customs records}

Our second source of data is customs records of Irish merchandise exports for the years 19962014. The value (euros) and quantity (tonnes) ${ }^{21}$ of exports are available at the level of the VAT number, the Combined Nomenclature (CN) eight-digit product, and the destination market (country), aggregated to an annual frequency. These data are matched by the CSO to CIP firms using a correspondence between VAT numbers and CIP firm identifiers, along with other confidential information. Appendix D provides additional information on this match. We make use of all matched records.

\footnotetext{
${ }^{20}$ Multiplant firms also fill in returns at the level of individual plants. We work with the firm-level data, since this is the level at which the match with customs records can be performed.

${ }^{21}$ The value is always available, but quantity is missing for about $10 \%$ of export records. For a limited set of observations, an additional quantity measure (besides tonnes) is available. We make use of this for robustness checks.
} 
Data for intra-EU and extra-EU trade are collected using two different systems called Intrastat and Extrastat. The threshold for mandatory reporting of intra-EU exports (635,000 euro per year in total shipments within the EU) is different from the threshold for extra-EU exports (254 euro per transaction). ${ }^{22}$ The high threshold for intra-EU exports likely leads to censoring of exports by small exporters to the EU. However unlike the extra-EU threshold, it applies not at the market level, but to exports to the EU as a whole. We observe many firms reporting exports which fall below the 635,000 euro threshold to individual EU markets. In any case, censoring of export participation is not a concern for our empirical strategy

An important feature of the customs data is that the eight-digit CN classification system changes every year. In order to be able to make time-series comparisions, we concord the product-level data over time at the most disaggregated level possible following the approach of Pierce and Schott (2012) and Van Beveren et al. (2012). ${ }^{23}$ The breakdown of Irish exports by HS 2-digit classification over the sample period is reported in Appendix D (Table 6).

For our baseline analysis, we restrict attention to the period 1996-2009, for which we have CIP data in addition to customs data, and for this analysis we make use only of customs data that matches to a CIP firm. In some robustness checks, we make use of the full sample period, 1996-2014. When we do so, we do not condition on a CIP match. We perform the product concordance separately for the two different sample periods, as dictated by the Pierce and Schott approach.

As a result, we have annual data on the value and quantity of exports at the firmproduct-market level, where the product is defined at the eight-digit (concorded) level, and the market refers to the destination country. We use this to construct a price (unit value) by dividing value by quantity, where available. In aggregate trade statistics, unit value data at the product level are notoriously noisy. However, conditioning on the exporting firm as well as the product considerably reduces this noise. ${ }^{24}$

\subsection{Summary statistics}

Table 1 shows summary statistics on exporting behavior in our data. Export participation is high, export intensity conditional on participation is high, and more than half of exporters participate in multiple markets (we observe 141 distinct export markets over the course of

\footnotetext{
${ }^{22}$ Intra-EU exports below the threshold are recovered based on VAT returns. The destination market within the EU is not recorded for these returns.

${ }^{23}$ We examine robustness to conditioning on products for which the concordance is 1-1 for all pairs of years in the sample.

${ }^{24}$ We check that our results are robust to dropping unit value outliers.
} 
the panel). These facts are typical of small open European economies (see ISGEP (2008)).

There is a good deal of churn in export participation at the firm-market level, and entry and exit are not synchronized across different export markets within a given firm. ${ }^{25}$ This is illustrated in Table 2, which reports summary statistics on churn in the number of export markets from year to year. In any given year, on average $49 \%$ of exporters change the number of markets they participate in. This is a lower bound on churn, as firms may keep the total number of export markets constant, while switching between markets. This churn is consistent with stochastic fixed and sunk costs of the type we include in our models. Fitzgerald and Haller (2018) document additional facts about entry and exit at the firmmarket and firm-product-market level.

Two key elements in our empirical strategy are the use of export spell duration $\left(l_{t}^{i j k}\right)$ as a proxy for the permanent component of idiosyncratic demand, and the use of number of markets per firm $\left(m^{i}\right)$ and number of firms per market $\left(f^{k}\right)$ as proxies for unobserved heterogeneity at the firm and market levels.

We confirm that $m^{i}$ and $f^{k}$ are correlated with alternative measures of firm- and marketlevel heterogeneity. Table 3 reports the correlation of $m^{i}$, with log average employment, average sales per worker and average revenue-based TFP, at the firm level (averages are taken over all the periods the firm is present in the CIP). It also reports the correlations between $f^{k}$ and market $k$ 's share in world GDP (average over the sample period), and the bilateral distance between Ireland and market $k$, at the market level. ${ }^{26}$ We find that $m^{i}$ is positively correlated with log employment, sales per worker and TFP, giving us confidence that it captures an important dimension of the firm's underlying cost advantage. In addition, $f^{k}$ is strongly positively correlated with market $k$ 's share in world GDP and negatively correlated with market $k$ 's distance from Ireland, giving us confidence that it summarizes the attractiveness of market $k$ to Irish firms.

Table 3 also reports the correlations of the firm- and market-level proxies with each other. At the export spell level, $m^{i}$ and $f^{k}$ are negatively correlated with each other, consistent with "bad" firms exporting only to "good" markets, and conversely, only "good" firms exporting to "bad" markets. This is in line with what we expect based on our models.

In Table 4, we report the distribution of duration across export spells and across export observations. Short-duration spells account for a large fraction of spells, but a substantially smaller fraction of export observations. In Table 5, we regress duration on $m^{i}$ and $f^{k}$. As we expect, the coefficients on $m^{i}$ and $f^{k}$ are positive and strongly significant. However the

\footnotetext{
${ }^{25}$ This is consistent with Lawless (2009), who uses a different data set for a selected sample of Irish firms.
}

${ }^{26}$ See Appendix D for more information on data sources and construction. 
R-squared of the regression is less than $1 \%$. Conditional on entry, firm- and market-specific heterogeneity does not account for much of the variation in duration. Unlike $m^{i}$ and $f^{k}$, we do not have alternative proxies for idiosyncratic demand with which to compare duration. But the fact that there is a good deal of residual variation in duration conditional on $m^{i}$ and $f^{k}$ is consistent with an important role for selection on idiosyncratic demand.

\section{$5 \quad$ Reduced form results}

\subsection{Baseline results}

In Table 6, we report the results from estimating our baseline equation (8) with log quantity and log price as dependent variables. In addition, we report results with log revenue as the dependent variable, and results from estimating this equation at the firm-market level, with $\log$ revenue and log number of products as independent variables. The estimation sample at the firm-product-market level covers $75 \%$ of exports, while the estimation sample at the firm-market level covers $99 \%$ of exports (Appendix Table 8 compares summary statistics for the estimation samples with summary statistics for the full data set).

We report the results in the form of fitted values of the relevant independent variables at all possible combinations of tenure and duration, evaluated at the mean values of our proxies for costs and market size across all firm-product-market-year observations, i.e. $\left\{\bar{m}^{i}, \bar{f}^{k}\right\} .{ }^{27}$ Full results are reported in Appendix Tables 9-13.

The omitted category in all regressions is export spells which last one year. The log of the dependent variable for these spells is therefore normalized to 0 . We organize our results into initial values conditional on duration relative to 1-year spells (in the first panel) and within-spell dynamics, normalizing the first year to 0 (the subsequent panels, one panel for each duration). Figures 1, and 2 graph the trajectories of quantities and prices implied by taking the exponential of the relevant sums of coefficients from Table $6 .{ }^{28}$

Four key findings emerge from Table 6 and Figures 1 and 2. First, quantity on entry is increasing in duration. Second, markups on entry are not systematically related to duration. Third, dynamics differ across spells of different duration, and quantity grows fourfold between years one and five of export spells that last at least seven years. This growth is statistically

\footnotetext{
${ }^{27} \bar{m}^{i}$ is at the 96 th percentile in terms of exporting firms, at the 57 th percentile in terms of export spells, and at the 55 th percentile in terms of export observations. $\bar{f}^{k}$ is at the 95 th percentile of export markets, at the 63rd percentile of export spells, and at the 59th percentile of export observations.

${ }^{28} \mathrm{We}$ include exponentials of standard errors in the quantity figure. To make the price figure easier to read, we include only standard errors for the longest spell.
} 
significant up to a horizon of four years and is not driven purely by part-year effects in the first year i.e. there is economically and statistically significant growth between years two and four. Fourth, within export spells that last at least seven years, there are no systematic dynamics in markups up to a horizon of six years. ${ }^{29}$

Table 6 also shows that the evolution of revenue at the firm-market level is qualitatively very similar to the evolution of revenue at the firm-product-market level. At the firm-market level, the trajectories are somewhat steeper, reflecting the fact that the number of products per market also evolves with market tenure. Focusing on the longest spells, around 3/4 of the growth of revenue at the market level between years one and six is accounted for by within-product growth in revenue, ${ }^{30}$ indicating that the within-product margin is of firstorder importance in explaining export growth.

Next we confirm that there is a decreasing hazard of exit conditional on firm- and marketspecific heterogeneity. The first column of Table 7 reports the fitted values of the exit hazard at the firm-product-market level, evaluated at $\left\{\bar{m}^{i}, \bar{f}^{k}\right\}$. The second column reports the analogous exit hazard at the firm-market level. These are based on estimating equation (9) at the firm-product-market and at the firm-market level. The omitted category is observations in their first year of export participation, so the exit probability is normalized to 0 for tenure equal to 1 . Figure 3 graphs both exit hazards. Again, full results are reported in the Appendix (Tables 16 and 19). ${ }^{31}$

Conditional on firm- and market-specific heterogeneity, the probability of exit at both firm-product-market and firm-market levels is initially steeply decreasing in market tenure. This is consistent with selection on the permanent component of idiosyncratic demand. This both implies that it is important to control for this dimension of heterogeneity to isolate dynamics, and justifies our use of duration a proxy for the idiosyncratic demand.

In Table 8, we report entry rates and 1-year exit rates conditional on $\mathrm{t}\left\{\bar{m}^{i}, \bar{f}^{k}\right\}$. These are moments we will match in the structural estimation. ${ }^{32}$

\footnotetext{
${ }^{29}$ Quantity on entry is increasing in $f^{k}$. Markups on entry are unrelated to either $m^{i}$ or $f^{k}$. We do not see evidence of a systematic relationship between dynamics in either quantity or markups and $m^{i}$ or $f^{k}$.

$3075 \%$ is obtained using the calculation $\exp (1.44-0.28)$ / $\exp (1.44)$. This is consistent with the findings of Hottman, Redding, and Weinstein (2016) on the importance of the product extensive margin.

${ }^{31}$ At the firm-product-market level, the exit hazard is less steeply decreasing for high $m^{i}$ firms than for low $m^{i}$ firms. At the firm-market level, the exit hazard is less steeply decreasing for high $m^{i}$ firms and high $f^{k}$ markets than for low $m^{i}$ firms and low $f^{k}$ markets.

${ }^{32}$ At both levels, entry is increasing in $m^{i}$ and $f^{k}$, while exit is decreasing in $m^{i}$ and $f^{k}$.
} 


\subsection{Implications of our baseline results}

The behavior of quantities in Table 6 and Figure 1, both the increasing relationship between initial quantities and duration, and the evolution of quantities with tenure, make it clear that demand plays an important role in post-entry export behavior. Since we control for firmproduct-year fixed effects and for higher-order effects of firm-specific heterogeneity through $m^{i}$, this behavior is not due to any supply-side factors. The increasing relationship between initial quantities and duration is consistent with selection on permanent heterogeneity in idiosyncratic demand. This is a feature of both of our candidate models, as shown in Proposition 1 and Proposition 2. Meanwhile, the growth of quantities with tenure in the longest export spells is consistent with high investment in customer base in firm-product-markets where idiosyncratic demand is high. This property of quantity dynamics is also consistent with both of our candidate models.

As regards markups, remember that in the marketing and advertising model, the markup of an entrant is independent of the permanent component of idiosyncratic demand, marginal cost, and market size, and there are no dynamics in markups. In the customer markets model, for firms that enter a market with less than steady state customer base, conditional on the permanent component of marginal cost and market size, the markup of an entrant is decreasing in the permanent component of idiosyncratic demand. In addition, conditional on survival, and the permanent component of idiosyncratic demand, marginal cost and market size, markups rise with tenure in a market. The behavior of markups in Table 6 and Figure 2 appears more consistent with the marketing and advertising model. There is no statistically significant relationship between initial markups and duration, nor do we find evidence of systematic dynamics in markups conditional on firm-product-year effects and duration. If anything, markups in the longest export spells appear to be weakly decreasing in tenure rather than increasing (this is statistically significant only in years $7+$ of the longest spells). Note that the lack of statistical significance is not due to noise: these are relatively precisely estimated zeros.

Of course, while the behavior of markups is qualitatively more consistent with the marketing and advertising model than the customer markets model, we also want to provide a more formal test. We do this by structurally estimating the two models. But first, we examine the robustness of our baseline results along a number of dimensions, and compare our findings with those in the related literature. 


\subsection{Building up our specification}

Our empirical strategy has many elements. To illustrate the role of each element, we now build it up step-by-step. As a benchmark, we regress log quantities and prices on firmproduct-year and product-market-year fixed effects, without any other controls. These fixed effects explain a substantial fraction of the variation in the data: $78 \%$ for quantities, and $87 \%$ for prices.

Next, we add our controls one-by-one. The results for quantities are reported in Table 9, while results for prices are reported in Table 10. We start by regressing log quantities and prices on the two sets of fixed effects, and a set of indicator variables for duration and censored duration. Results for this specification are in column (1). Then, we regress $\log$ quantities and prices on the fixed effects, a set of indicator variables for tenure, an indicator for censored duration, and a dummy for future exit. The exit dummy allows for nonlinear dynamics prior to exit. Results are in column (2). After that, we include indicator variables for duration, tenure, censored spells, and the exit dummy. Results are in column (3). Then, we include the full set of interactions between duration and age, in addition to the censored spell indicators. In column (4) we report the resulting coefficients on duration at tenure equal to 1 , and the coefficients on tenure for spells of duration $7+$ years (Full results are in Appendix Table 20,). Finally, in column (5), we reproduce the corresponding coefficients from our baseline specification, which interacts the duration-specific trajectories with $m^{i}$ and $f^{k}$, and evaluates the trajectories at $\bar{m}^{i}$ and $\bar{f}^{k}$.

From this exercise we learn that for quantities, inference about the magniture of unobserved heterogeneity, and the nature of dynamics is sensitive to the specification used. Both unobserved heterogeneity and dynamics appear to be present, so failure to control for one leads to misleading inference about the other. Based on specification (1), we might infer a greater degree of unobserved heterogeneity than is actually present, because dynamics are ignored. Based on specification (2), we might infer more dramatic growth in quantities than actually takes place, because we fail to take account of the fact that initial quantities are systematically lower in short spells than in long spells. Comparing specification (3) with specifications (4) and (5) illustrates that controlling for both duration and tenure is not sufficient. If we do not allow dynamics to vary with duration, we might not do too badly in capturing the dynamics in long spells, but we would draw very misleading inference about heterogeneity in idiosyncratic demand and the nature of selection. Finally, allowing dynamics to vary with costs and market size, as well as duration, as we do in our baseline specification (5), affects our understanding of the degree of heterogeneity in idiosyncratic 
demand, but does not much affect our understanding of dynamics.

In the case of prices, none of the controls add much in terms of $\mathrm{R}^{2}$. Irrespective of specification, markups do not appear to be systematically related to heterogeneity in idiosyncratic demand, nor do we find evidence of systematic dynamics in markups.

\subsection{Robustness}

Next, we perform a series of robustness checks on our baseline analysis. These include estimation of alternative empirical specifications, and estimation of our baseline specification on different subsamples. We briefly describe here the results of these exercises. The relevant tables are reported in Appendix F and the relevant figures are reported in Appendix G.

\subsubsection{Specification robustness}

We experiment with alternatives to our baseline proxies for marginal cost and market size $\left(m^{i}\right.$ and $\left.f^{k}\right)$. Results are very similar when we use logs instead of levels of the number of markets per firm and number of firms per market. Results for the firm-product-market-level specifications are also very similar when we use the number of markets per firm-product and the number of firms per product-market $\left(m^{i j}\right.$ and $\left.f^{j k}\right)$ as interactions instead of $m^{i}$ and $f^{k}$.

We estimate a specification which includes firm-product-market-spell fixed effects to control for the first order effect of idiosyncratic demand (though we allow trajectories to vary with duration, $m^{i}$, and $f^{k}$ as in the baseline). This specification uses only within-spell variation in tenure to identify dynamics. It cannot identify how initial quantities and markups are related to idiosyncratic demand through duration. If anything, the dynamics in quantities identified using this approach are a little steeper than those based on our baseline specification, while the behavior of markups is very similar to the baseline.

We estimate a specification where we drop unit value outliers. Our criterion for an outlier is an observation where the absolute value of the the log change in the unit value between the current and previous period exceeds 2 . Results are very similar to the baseline. We also

estimate a specification where we use only observations which have a measure of quantity which is not "tonnes" (the default measure of quantity). This reduces the sample size by a factor of 8 , and results are very noisy as a result.

We estimate a specification where we topcode tenure and duration at 10 years rather than at 7 years. To do so, we make use of the longer sample of customs data (1996-2014) which is not matched to CIP firms. The behavior of quantities and markups is qualitatively very similar to the baseline using this specification and data. 


\subsubsection{Firm, product, and market characteristics}

Foreign multinationals have a substantial presence in Ireland, especially in the manufacturing sector. They are export-intensive (mainly platform FDI) and due to this, account for 55\% of the firms in our baseline analysis of quantities and prices. We check that the behavior of export quantities, prices, and exit is the same for domestic-owned and for foreign-owned firms by splitting the sample, and re-estimating on the two subsamples. Results are very similar across the two groups of firms.

It is possible that the importance of marketing and advertising relative to markup distortions in accumulating customer base could differ across sectors. We split the sample into four broad sectors, two consumer-facing (consumer food, consumer non-food non-durables), and two business-facing (intermediate goods, capital goods), and estimate our baseline equation separately for each sector. Splitting the sample in this way greatly reduces sample size, and results are correspondingly noisy. However they are consistent with the baseline in all sectors.

We also check whether results are similar for markets which are close, and for which trade barriers are low, ${ }^{33}$ and for markets which are distant, and barriers are greater. We do this by splitting the sample into EU markets (Intrastat) and non-EU markets (Extrastat). Results are very similar for the two different samples.

\subsubsection{Are our results driven by special features of the Irish data?}

One possible concern is that our results may be due to some special features of the Irish data. To alleviate such concerns, we note that we can replicate the findings of a large body of literature working with firm and customs micro data for other countries. As mentioned above, summary statistics on the cross-sectional dimension of exporting in our data are in line with those for other small open European economies. Our findings on the post-entry dynamics of revenues and exit are consistent with those in the previous literature, (e.g., Eaton et al. (2014), Ruhl and Willis (2017)). Using our data, we can also replicate a number of facts about the behavior of unit values in customs data for other countries. We find that in the cross-section, export prices vary with destination market characteristics just as in the literature surveyed in Harrigan et al. (2015). Meanwhile, in Fitzgerald et al. (2019), we show that the degree of pricing-to-market in our data is very similar to that for other countries (e.g. France, as shown by Berman et al. (2012)). The consistency of these findings

\footnotetext{
${ }^{33}$ Note that as long as trade barriers are the same for all firms selling a given product to a given market, they are captured by the product-market-year fixed effects.
} 
with those based on other data sets suggests to us that our results cannot be attributed to special features of the Irish data.

\subsection{Relation to the empirical literature on price dynamics}

A series of papers prior to and contemporaneous with ours investigate price dynamics in a variety of empirical settings. Some of these papers arrive at results which appear to differ from ours. Foster et al. (2008) use the quinquennial U.S. manufacturing census data on plants in a narrow set of commodity-like sectors, and find that older plants have higher prices. Using customs data for France, Berman et al. (2019) show a decreasing relationship between prices and tenure in an export market. Piveteau (2019) uses French customs data, and concludes that prices are increasing with tenure in a market. Bastos et al. (2018) use Portuguese customs data, and conclude that prices are decreasing with tenure. That said, none of these papers find evidence of quantitatively significant dynamics, and their findings mostly lie within our standard error bands. Meanwhile, Argente, Lee and Moreira (2019) and Fitzgerald and Priolo (2018) use Nielsen data for the U.S., and present evidence on the behavior of prices that is very similar to what we find.

We hypothesize that these contrasting results are due at least partially to the fact that (with the exception of Fitzgerald and Priolo (2018)) each of these papers uses an empirical specification which differs from ours. In particular, the specifications which do not control for firm- or firm-product-level unobserved heterogeneity (Foster et al. (2008), and a 2016 version of Piveteau's paper) find an increasing relationship between prices and tenure. To confirm the hypothesis that the failure to control for this dimension of heterogeneity may be responsible for the increasing relationship these authors find, we estimate specifications which resemble those of Foster et al. and Piveteau (2016) using our data. Results are reported in Table 11. We find an increasing (though not always statistically significant) relationship between prices and tenure using these specifications. We hypothesize that this may be due to selection on quality, or to quality upgrading by successful firms. Both of these are controlled for in our baseline specification by the inclusion of firm-product-year fixed effects.

Piveteau (2019) uses a specification which differs from his earlier approach by pooling all observations, and controlling for firm-product-year as well as product-market-year fixed effects. With this specification, he finds that prices in observations with tenure of 7 years are $4 \%$ higher than prices in observations which have just entered. We cannot replicate this finding in our data, as we show in column (3) of Table 11. 
Berman et al. (2019) regress log prices at the firm-product-market level on firm-productyear fixed effects and indicators for tenure, pooling across all observations. They find a negative and statistically significant relationship between prices and tenure: prices in observations with tenure greater than one are lower than prices in observations with tenure of one, and this difference is statistically significant at all horizons. In particular, prices in observations with tenure of seven are $7 \%$ lower than prices in observations with tenure of one. These results are similar to ours, with the distinction that they find statistical significance at horizons between two and six years, while we do not. This may be due to the fact that they are working with a much bigger data set. We implement their specification in column (4) of Table 11, and find results very similar to our baseline.

Bastos et al. (2018) take a quite different approach to the other authors. They first regress log export prices on product-market-year and firm-market-year fixed effects. They then use the firm-market-year fixed effects as the dependent variable in a regression where they include the log of firm-market tenure, or the log of firm-market tenure and firm-year and market fixed effects on the right hand side. Using both specifications, they find a negative relationship between prices and tenure. This specification differs from ours along many dimensions, and we do not attempt to replicate it. However we note that their findings are quantitatively similar to ours.

Finally, Fitzgerald and Priolo (2018) use Nielsen data on consumer food sales in 206 distinct geographical markets in the U.S. to estimate a restricted version of our baseline specification (they do not interact the vector of duration-tenure indicators with proxies for firm- and market-level heterogeneity). They find that markups are invariant to tenure, with the exception of markup declines immediately before exit from a market. These appear to be associated with fire-sales at the store level.

\section{Structural estimation and results}

We now turn to structural estimation of the two models proposed in Section 2 by simulated method of moments.

\subsection{Assumptions about distributions and functional forms}

As described above, we construct a set of moments on the behavior of quantities, markups, and the exit hazard that are evaluated for a hypothetical firm with constant marginal cost and a hypothetical market with constant market size. This allows us to abstract from 
variation in marginal cost and market size, so we normalize both costs $\left(C_{t}^{i}\right)$ and market size $\left(Y_{t}^{k}=Q_{t}^{k}\left(P_{t}^{k}\right)^{\theta}\right)$ to 1 .

We assume the following process for idiosyncratic demand: $\nu_{t}^{i k}=\bar{\nu}^{i k}+\tilde{\nu}_{t}^{i k}$, where $\bar{\nu}^{i k} \sim$ $N\left(0, \sigma_{\nu}^{2}\right)$ and $\tilde{\nu}_{t}^{i k}=\rho \tilde{\nu}_{t-1}^{i k}+\eta_{t}^{i k}$, with $\eta_{t}^{i k} \sim N\left(0, \sigma_{\eta}^{2}\right)$. We assume a very simple process for the sunk cost, $S_{t}^{i k}$ :

$$
S_{t}^{i k}= \begin{cases}0 & \text { with probability } \lambda \\ \infty & \text { with probability } 1-\lambda\end{cases}
$$

where $\lambda \in[0,1]$. With probability $\lambda$, entry is possible, while with probability $1-\lambda$, entry is not possible. In the absence of cost and market size heterogeneity, this assumption is without loss of generality. Note that just because entry is possible, it does not mean that a firm will choose to enter a market. The decision to enter depends also on the realizations of the fixed cost, $F_{t}^{i k}$ and $\left\{\bar{\nu}^{i k}, \tilde{\nu}_{t}^{i k}\right\}$. For the fixed cost, we assume the following process:

$$
F_{t}^{i k}= \begin{cases}0 & \text { with probability }(1-\omega) \gamma \\ F & \text { with probability }(1-\omega)(1-\gamma) \\ \infty & \text { with probability } \omega\end{cases}
$$

where $\omega \in[0,1]$ and $\gamma \in[0,1]$. If $\gamma<1$ and $0<\omega<1$, this process generates both exogenous and endogenous exit. If $0<\gamma<1$, it contributes to selection on idiosyncratic demand and a downward-sloping exit hazard because a firm may participate in a market where idiosyncratic demand is weak as long as $F_{t}^{i k}=0$, but as soon as it draws a realization of $F_{t}^{i k}=F$, exit is triggered. In contrast, in markets where idiosyncratic demand is strong, the firm will continue to participate as long as $F<\infty$.

In the marketing and advertising model, we assume that the cost of investment takes the form:

$$
c\left(D_{t}^{i k}, A_{t}^{i k}\right)= \begin{cases}A_{t}^{i k}+\phi \frac{\left(A_{t}^{i k}\right)^{2}}{D_{t}^{i k}} & \text { if } A_{t}^{i k}>0 \\ 0 & \text { otherwise }\end{cases}
$$

This builds in quadratic adjustment costs, as is standard, and irreversibility, which makes sense in the context of intangible investment. In the robustness checks, we investigate the implications of alternative adjustment cost functions. 


\subsection{Estimation}

Our estimation approach is the same for both models. Given values for the parameters, we discretize both exogenous and endogenous states ${ }^{34}$ and use value function iteration to solve for the optimal policies. Using the model parameters and the corresponding optimal policies, we then simulate post-entry trajectories for 10,000 "firm-markets." To account for the fact that there are part-year effects in the data, the length of a period in our model is 6 months. We stagger entry across 6 -month periods, and aggregate up to an annual frequency to construct the equivalents of the moments we report in Section 5. The goal of our estimation is to choose the vector of parameters that best matches these moments.

We match the following 59 moments: the ratios of initial quantities and initial markups across spells of different length to quantities and markups in 1-year spells; the evolution of quantities and markups with tenure for export spells of different duration; the evolution of exit probabilities at the firm-market level with tenure, normalized by the exit probability in the first year; the rate of entry at the firm-market level, and the exit rate in the first year in a market, also at the firm-market level. ${ }^{35}$

We preset the rate at which firms discount the future. Since the period length is 6 months, we set $\beta=1.05^{-0.5}$. There are then 11 parameters to be estimated in the marketing and advertising model: $\left\{\sigma_{\nu}^{2}, \sigma_{\eta}^{2}, \rho, \lambda, F, \omega, \gamma, \underline{D}, \alpha, \delta, \phi\right\}$. Note that in this model, $\theta$ is not identified by the moments we use as targets, since with fixed marginal cost and constant markups, all changes in quantity are driven by shifts in demand rather than movements along the demand curve. There are also 11 parameters to be estimated in the customer markets model: $\left\{\sigma_{\nu}^{2}, \sigma_{\eta}^{2}, \rho, \lambda, F, \omega, \gamma, \underline{D}, \alpha, \delta, \theta\right\}$. In each case, we choose the relevant set of parameters to minimize the criterion function $m^{\prime} V m$, where $m$ is the difference between the data moments and the equivalent moments in the model, and $V$ is a diagonal matrix, with the inverse of the standard deviation of the estimates of the data moments on the diagonal. We use a combination of a particle swarm algorithm and the simplex method to optimize over the parameter vector.

\footnotetext{
${ }^{34}$ We use three states each for the permanent and transitory idiosyncratic demand shocks $(\nu$ and $\eta)$. The grid for customer base depends on parameter values.

${ }^{35}$ We match entry and exit moments at the firm-market level rather than at the firm-product-market level because we do not wish to address the role of the extensive margin of products in our analysis.
} 


\subsection{Baseline results}

Table 12 reports the estimated parameters and the optimized value of the criterion function $m^{\prime} V m$ for both models. ${ }^{36}$ Figures 4,5 and 6 illustrate the fit of the two models for quantities, prices and exit. The corresponding tables are reported in Appendix H (Tables 59 and 60).

The marketing and advertising model provides a good fit to all moments. It can generate dispersion in initial quantities that is positively correlated with spell duration, and of the right order of magnitude. Quantities increase with tenure in successful spells as in the data. By construction, initial markups are uncorrelated with spell duration, and markups are flat with respect to market tenure. The exit hazard closely matches the data, and the rate of entry matches that in the data.

In this model, the trade elasticity (i.e. the long-run elasticity of exports with respect to e.g. tariffs) is given by $\theta /(1-\alpha)$. Since we cannot identify $\theta$, the trade elasticity is not pinned down by our estimates. But combining our estimate of $\alpha$ with price elasticities of demand in the range 1.5 to 4 , we obtain trade elasticities in the range 3 to 8 , consistent with what is found in the literature.

The customer markets model generates more limited dispersion in initial quantities with duration, and more limited growth in quantities in spells that last $7+$ years than the marketing and advertising model. This is despite the fact that we estimate a very high value for the price elasticity of demand, i.e. 32. Although it is not apparent in the figures, markups do in fact rise with tenure in the longest spells in this model. Intuitively, to match growth in quantities in the longest export spells while minimizing the increase in markups with tenure, tiny changes in markups must induce very big changes in sales, and hence big shifts in future demand.

The estimated value for the price elasticity of demand in this model is well outside the range of commonly accepted values in the literature. The implied trade elasticity is given by $\theta /(1-\alpha)=102$. This is one to two orders of magnitude greater than the range of trade elasticities used in the trade literature, which mostly lie between 3 to 12 . It is dramatically higher than the trade elasticity estimated by Fitzgerald and Haller (2018) using responses to tariff changes in the very same Irish customs data. We take this extreme parameter estimate as an indication that the markup channel is unlikely to play an important role in customer base accumulation.

Our structural estimates thus confirm the findings of our reduced form analysis, and

\footnotetext{
${ }^{36}$ We report standard errors constructed using the method suggested by Gourieroux et al. (1993). Details of this method are reported in Appendix E.
} 
suggest that firms use non-price activities such as marketing and advertising rather than markups to accumulate customer base and increase market share.

\subsection{Selling expenses}

An advantage of structural estimation is that we can use our estimates of the marketing and advertising model to back out the ratio of selling expenses to revenue net of total marginal cost:

$$
\operatorname{sell}_{t}^{i k}=\frac{c\left(D_{t}^{i k}, A_{t}^{i k}\right)}{\left(P_{t}^{i k}-C_{t}^{i}\right) Q_{t}^{i k}}
$$

In Figure 7, we show the evolution of this ratio for export spells of different duration. Expressed in this way, selling expenses are highest at the beginning of an export spell, and decline with tenure thereafter. Initial selling expenses are also higher in spells that are ultimately successful than in spells that are ultimately unsuccessful, as firms invest more when idiosyncratic demand, and therefore desired future customer base is higher.

In the data, selling expenses are usually expressed as a share of revenue rather than as a share of revenue net of total marginal cost. In the marketing and advertising model, the ratio of revenue to revenue net of total marginal cost is equal to the price elasticity of demand, $\theta$. So in order to compare the absolute level of selling expenses in the model with that in the data, we need to take a stand on $\theta$. Assuming $\theta=3$, our estimates suggest that selling expenses on average account for $15 \%$ of revenue in the 6 th year of export spells that last $7+$ years.

We do not have any data on selling expenses for our firms, but Arkolakis (2010) calculates that marketing and advertising expenditures may account for $7-8 \%$ of U.S. GDP. The CMO Survey of chief marketing officers in the U.S. finds that over the period 2008-2018, firms in goods-producing sectors report spending between $7 \%$ and $11 \%$ of revenue on marketing. ${ }^{37}$ As reported in the Introduction, Gourio and Rudanko (2014) note that the share of Selling, General \& Administrative expenses in total revenue for Compustat firms is even higher, on the order of $17-27 \%$. Traina (2018) notes that this share has increased from $12 \%$ on average in 1950 to $22 \%$ today. In this context, our estimates for the share of selling expenses in revenue are quite reasonable.

Selling expenses of the size we estimate could generate substantial mismeasurement of productivity if not correctly accounted for. Of course, if mismeasurement is constant across

\footnotetext{
${ }^{37}$ See answers to the question "Marketing expenses account for what percent of your firm's revenues?" for goods-producing firms selling business-to-business and business-to-consumer.
} 
firms and over time, this is unlikely to be a problem. But our estimates suggest that mismeasurement disproportionately affects entrants. Taking the selling expense ratios from spells of duration $7+$ years as a benchmark, and again assuming a price elasticity of demand equal to 3, a firm in our simulated data with the selling expense ratio of an entrant would have measured productivity (both physical productivity and revenue productivity) $7.5 \%$ lower than that of an incumbent of 6 years' standing, even though true productivity is identical for both. ${ }^{38}$

\subsection{Robustness}

Full details of all robustness exercises are reported in Appendix H (tables) and Appendix I (figures).

As noted in Section 3, part-year effects may contribute to the appearance of dynamics even if there are no true underlying dynamics. We build part-year effects into both of our models by having firms make decisions about 6-month periods, staggering entry across 6-month periods, and aggregating up to the calendar year in constructing our moments. We examine the contribution of part-year effects to dynamics by contrasting our baseline predictions with those obtained when we use the same parameter estimates, but shut down part-year effects. We do this by categorizing export spells by their true duration and looking at the evolution of quantities, prices, and exit with true tenure. In both models, part-year effects magnify the appearance of dispersion of quantities on entry as well as growth in quantities in the longest export spells. But dynamics in quantities are still quantitatively important when part-year effects are shut down.

We also estimate restricted versions of our two models to help illustrate their key features. For the marketing and advertising model, we focus on adjustment costs. When we fix $\phi=0$, the model can generate dispersion in inital quantities, and does a good job of matching entry and exit, but does not generate any significant dynamics in quantities beyond the first period. This illustrates the fact that adjustment costs are key to slow adjustment in the model. Although it is natural to assume irreversibility for intangible investment, it turns out not to be fundamental to fitting the moments: we obtain a reasonable fit and similar preditions for selling expenses under full reversibility. Given its importance, we also re-estimate with an alternative functional form for the adjustment cost function: $c\left(D_{t}^{i k}, A_{t}^{i k}\right)=A_{t}^{i k}+\phi\left(\frac{A_{t}^{i k}}{D_{t}^{i k}}-\delta\right)^{2} D_{t}^{i k}$. Using this functional form, we obtain a slightly poorer fit to the data moments. In addition, initial selling expenses are higher than under

\footnotetext{
${ }^{38}$ This is based on calculating TFP using $C Q /(C Q+c(C, D))$.
} 
our baseline formulation, though in the absence of data on selling expenses to discipline this moment, it is not clear which functional form is preferable.

For the customer markets model, a key question is the extent to which the model can provide a reasonable fit to the data with a value for the trade elasticity that lies in the range used in the trade literature. To investigate this question, we re-estimate the model, constraining the trade elasticity $\theta /(1-\alpha)$ to be equal to 5 . Under this constraint, the fit of the model deteriorates markedly. The dispersion of initial quantities and quantity growth in the longest spells fall. Initial markups in the longest spells start lower than markups in the shortest spells, and grow with tenure (though the magnitude of this effect is still very modest). From this exercise, we learn that this model needs large values for the price elasticity of demand in order to jointly match the behavior of quantities and markups.

\subsection{A non-nested alternative model: learning about demand}

The literature on international trade has proposed learning about idiosyncratic demand as a potential explanation for the post-entry behavior of export quantities and prices. ${ }^{39}$ Unlike the marketing and advertising model and the customer markets model, the learning model has not been extensively applied outside the exporting environment. This model is not nested in either of the two alternatives we have considered so far. The central idea is that idiosyncratic demand has two components: permanent, and transitory. If the permanent component of idiosyncratic demand is high, it will be profitable to participate, while if it is low, participation will not be profitable. Prior to entry in a market, a firm has no information about either component. In order to learn its permanent idiosyncratic demand type, the firm must sell in the market.

Since the position of demand is uncertain, it matters whether the firm sets prices or quantities. In the case where it sets quantities, the firm learns from realized prices about the position of the demand curve. In the case where it sets prices, realized quantities reveal this information. Bayesian firms use the Kalman filter to update their beliefs about the permanent component of idiosyncratic demand based on these signals. If the firm sets quantities, after seeing a high initial price, it will infer that idiosyncratic demand is high. Next period, it will ship a greater quantity, and slide down its demand curve. After seeing a low initial price, the firm will infer that demand is low, and may exit that market. Thus, learning generates dynamics in quantities and prices, in addition to a downward-sloping exit hazard. In this quantity-setting case, duration and initial quantities are uncorrelated, while

\footnotetext{
${ }^{39}$ See e.g. Arkolakis et al. (2018) and Berman et al. (2019).
} 
duration and initial prices are positively correlated. Quantities rise with tenure, and prices decline with tenure in successful spells.

In Appendix $\mathrm{C}$, we describe a version of this model in detail. In Appendix $\mathrm{H}$ and Appendix I, we report the results from estimating it to match the same moments as the marketing and advertising and customer markets models. This model provides a very poor fit to the data. This is not surprising in the light of the fact that its predictions about the relationships between initial quantities and prices and duration are clearly counterfactual. In addition, our estimate of the price elasticity of demand in this model is counterfactually high, to match the fact that prices are basically flat, while there are very large changes in quantities.

\section{Implications and conclusion}

We use customs data for Ireland to show that successful entry into an export market is associated with substantial growth in quantities conditional on costs, but no change in markups. This is compelling evidence that customer base and demand play an important role in postentry dynamics. We compare two competing models of how firms accumulate customer base: a model of marketing and advertising, where firms use non-price actions to attract customers, and a customer markets model where firms use temporarily low markups to attract customers. On the face of it, the customer markets model is inconsistent with the absence of markup dynamics. We show this more formally by structurally estimating the two competing models. The marketing and advertising model fits the data well, and is consistent with reasonable values for the trade elasticity. The customer markets model has a slightly worse fit, but more importantly, parameter estimates imply a counterfactually high trade elasticity. Meanwhile, our estimates of the marketing and advertising model imply that successful entry into a new market is accompanied by high selling expenses, both relative to expenses in the case of unsuccessful entry, and relative to expenses in mature markets.

As explained in the introduction, it is important to establish which mechanism firms use to accumulate customers in new markets, because these two models have quite different implications for how successful entry might show up in measured productivity. If (as is often the case) inputs to production cannot be separated from inputs used in marketing and advertising, productivity may be systematically mismeasured for firms entering new markets relative to other firms. On the other hand, the customer markets model implies that market entry will be accompanied by low average markups, and hence low measured 
TFPR (revenue-based TFP), but no mismeasurement of TFPQ (physical productivity). To give just one application, understanding how firms build customer base could shed light on whether the post-2000 slowdown in measured productivity growth is linked to the wave of globalization and market integration over the same period, or whether it only deepens the puzzle of the contemporaneous increase in markups.

In different forms, the idea of "customer markets" has a long history in macroeconomics. It is used extensively in work that focuses on flexible-price markup-based explanations for the countercyclicality of the labor wedge in business cycles. The idea is that booms are times when there are many potential new customers, and to attract these customers, firms choose low markups (e.g. e.g. Bils (1989), Ravn et al (2006) and Gilchrist (2017)). While we cannot rule out that firms use markups to attract customers at a business cycle frequency, our results suggest that this mechanism does not play an important role in firm dynamics. In addition, by showing that entry and selling expenses are likely to be tightly linked, we provide a partial resolution to a puzzle posed by Hall (2014). He notes that advertising is procyclical, but that this is inconsistent with countercyclical markups, as firms are likely to advertise more when markups are high. In the context of our results, advertising is likely to be procyclical because it is associated with entry, and entry is procyclical. Meanwhile, there is no reason why entry should be associated with low markups, if firms do not use low markups to build customer base.

Beyond the specific areas of productivity measurement and markup cyclicality, our findings have potential implications for the many areas of macroeconomics and international economics where models with demand and customer base are used. Hottman et al. (2016) and Haltiwanger and Eslava (2019) decompose the sources of firm growth into contributions of marginal cost and demand. By modeling the relationship between exogenous marginal cost and idiosyncratic demand, and endogenous customer base, we provide pointers towards an alternative decomposition methodology that takes into account this endogeneity. Gourio and Rudanko use a hybrid of our two models to show that sluggish adjustment of customer base has important implications for firm responses to shocks, and for the relationship between investment and Tobin's Q. Drozd and Nosal (2012b) investigate the performance of the customer markets model in matching international business cycle comovements, and find it does poorly. In a direct application of our findings, Fitzgerald et al. (2019) show that the marketing and advertising model we estimate here has the potential to rationalize the very different responses of exports to movements in exchange rates and changes in tariffs that we see in the data. 


\section{References}

[1] Abraham, K. and S. Farber (1987), "Job Duration, Seniority, and Earnings" American Economic Review 77, 278-297.

[2] Argente, D., M. Lee and S. Moreira (2019), "How Do Firms Grow? The Life Cycle of Products Matters," mimeo.

[3] Arkolakis, C. (2010), "Market Penetration Costs and the New Consumers Margin in International Trade," Journal of Politicial Economy 118 (6), 1151-1199.

[4] Arkolakis, C. (2016), "A Unified Theory of Firm Selection and Growth," Quarterly Journal of Economics 131 (1), 89-155.

[5] Arkolakis, C., T. Papageorgiou, and O. Timoshenko (2018), "Firm Learning and Growth," Review of Economic Dynamics 27, 146-168.

[6] Bastos, P., D. A. Dias and O. Timoshenko (2018), "Learning, Prices, and Firm Dynamics," Canadian Journal of Economics 51, 1257-1311.

[7] Berman, N., P. Martin and T. Mayer (2012), "How Do Different Exporters React to Exchange Rate Changes," Quarterly Journal of Economics 127, 437-492.

[8] Berman, N., V. Rebeyrol, and V. Vicard (2019), "Demand Learning and Firm Dynamics: Evidence from Exporters," Review of Economics and Statistics 101, 91-106.

[9] Bils, M. (1989), "Pricing in a Customer Market," Quarterly Journal of Economics 104, 699-718.

[10] CMO Survey, Duke University, 2008-2018, cmosurvey.org

[11] De Loecker, J., J. Eeckhout and G. Unger (2019), "The Rise of Market Power and the Macroeconomic Implications," Quarterly Journal of Economics, forthcoming.

[12] Drozd, L. A., and J. B. Nosal (2012a), "Understanding International Prices: Customers as Capital," American Economic Review 102 (1), 364-395.

[13] Drozd, L. A., and J. B. Nosal (2012b), "Pricing-to-Market in Business Cycle Models," mimeo.

[14] Eaton, J., S. Kortum, and F. Kramarz (2011), "An Anatomy of International Trade: Evidence From French Firms," Econometrica 79 (5), 1453-1498. 
[15] Eaton, J., M. Eslava, D. Jinkins, C. Krizan, and J. R. Tybout (2014), "A Search and Learning Model of Export Dynamics," mimeo.

[16] Eslava, M. and J. Haltiwanger (2019), "The Life-Cycle Growth of Plants: The Role of Productivity, Demand and Wedges," mimeo.

[17] Fitzgerald, D. and S. Haller (2018), "Exporters and Shocks," Journal of International Economics 113, 154-171.

[18] Fitzgerald, D. and A. Priolo (2019), "How Do Firms Build Market Share?" mimeo.

[19] Fitzgerald, D., Y. Yedid-Levi and S. Haller (2019), "Can Sticky Quantities Explain Export Insensitivity to Exchange Rates?" mimeo.

[20] Foster, L., J. Haltiwanger, and C. Syverson (2008), "Reallocation, Firm Turnover, and Efficiency: Selection on Productivity or Profitability?" American Economic Review 98 (1), 394-425.

[21] Foster, L., J. Haltiwanger, and C. Syverson (2016), "The Slow Growth of New Plants: Learning About Demand," Economica 83, 91-129.

[22] Gilchrist, S., R. Schoenle, J. Sim and E. Zakrajsek (2017), "Inflation Dynamics During the Financial Crisis," American Economic Review 107 (3), 785-823.

[23] Gourieroux, C., A. Monfort and E. Renault (1993), "Indirect Inference," Journal of Applied Econometrics 8 (SI), 85-118.

[24] Gourio, F., and L. Rudanko (2014), "Customer Capital," Review of Economic Studies $81(3), 1102-1136$.

[25] Hall, R. (2014), "What the Cyclical Response of Advertising Reveals About Markups and Other Macroeconomic Wedges," NBER Working Paper 18370.

[26] Harrigan, J., X. Ma and V. Shlychkov (2015), "Export Prices of U.S. Firms," Journal of International Economics 97, 100-111.

[27] Hottman, C., S. Redding, and D. Weinstein (2016), "Quantifying the Sources of Firm Heterogeneity," Quarterly Journal of Economics 131, 1291-1364.

[28] ISGEP (2008), "Understanding Cross-Country Differences in Exporter Premia: Comparable Evidence for 14 Countries," Review of World Economics 144, 596-635. 
[29] Lawless, M. (2009), "Firm Export Dynamics and the Geography of Trade," Journal of International Economics 77 (2), 245-254.

[30] Pierce, J., and P. Schott (2012), "A Concordance Between Ten-Digit US Harmonized System Codes and SIC/NAICS Product Classes and Industries," Journal of Economic and Social Measurement 37 (1-2), 61-96.

[31] Piveteau, P. (2016), "An Empirical Dynamic Model of Trade with Customer Accumulation," mimeo.

[32] Piveteau, P. (2019), "An Empirical Dynamic Model of Trade with Customer Accumulation," mimeo.

[33] Ravn, M., S. Schmitt-Grohe, and M. Uribe (2006), "Deep Habits," Review of Economic Studies 73 (1), 195-218.

[34] Ruhl, K., and J. Willis (2017), "New Exporter Dynamics," International Economic Review 58, 703-726.

[35] Traina, J. (2018), "Is Aggregate Market Power Increasing? Production Trends using Financial Statements," mimeo.

[36] Van Beveren, I., A. B. Bernard and H. Vandenbussche (2012), "Concording EU Trade and Production Data over Time," mimeo. 
Table 1: Summary statistics: Firms and exports, averages 1996-2009

\begin{tabular}{l|c}
\hline Mean number of firms per year & 4748 \\
Mean employees & 50 \\
Mean age (years) & 17 \\
Share of firms foreign owned & 0.12 \\
Share of multi-plant firms & 0.03 \\
Mean number of concorded products per firm & 4 \\
\hline Share of firms exporting & 0.44 \\
Exporter size premium (employees, mean) & 1.65 \\
Exporter size premium (revenue, mean) & 1.85 \\
Mean export share conditional on exporting & 0.32 \\
Mean number of markets per exporter & 6.6 \\
\hline
\end{tabular}

Notes: Statistics are for our cleaned data set of CIP firms. Firms are defined as exporters if they are matched to positive concorded product exports from customs data. Export intensity is calculated as total concorded product exports from customs divided by sales reported in the CIP. Values greater than 1 are replaced by 1 . Source: CSO and authors' calculations.

Table 2: Percentage of exporters by change in number of markets year to year

\begin{tabular}{c|ccccccccccccc}
\hline Change & $<-6$ & -5 & -4 & -3 & -2 & -1 & 0 & 1 & 2 & 3 & 4 & 5 & $>6$ \\
\hline$\%$ & 2 & 1 & 2 & 3 & 5 & 11 & 51 & 11 & 5 & 3 & 2 & 1 & 3 \\
\hline
\end{tabular}

Notes: Statistics are for our cleaned data set of CIP firms. Firms are defined as exporters if they are matched to positive concorded product exports from customs data. Export revenue is concorded product export revenue from customs data. There are 140 export markets. Source: CSO and authors' calculations.

Table 3: Correlations of $m^{i}$ and $f^{k}$ with employment, GDP and distance

\begin{tabular}{l|cccc|ccc}
\hline & $m^{i}$ & Log emp. & Rev/worker & TFP & $f^{k}$ & Sh. GDP & Log dist. \\
\hline \# markets per firm $\left(m^{i}\right)$ & 1 & & & & & & \\
Log employment & 0.57 & 1 & & & & & \\
Rev/worker & 0.37 & 0.32 & 1 & & & & \\
TFP & 0.17 & 0.04 & 0.56 & 1 & & & \\
\hline \# firms per market $\left(f^{k}\right)$ & -0.29 & -0.10 & -0.16 & -0.12 & 1 & & 1 \\
Sh. world GDP & -0.15 & -0.05 & -0.11 & -0.06 & 0.67 & 1 \\
Log distance & 0.18 & 0.05 & 0.02 & 0.06 & -0.43 & -0.05 & 1 \\
\hline
\end{tabular}

Notes: For correlations between firm-level variables, an observation is a firm. For correlations between market-level variables, an observation is a market. For correlations between firm-level and market-level variables, an observation is an export spell at the firm-product-market level. Source: CSO and authors' calculations. 
Table 4: Distribution of duration: Export spells and export observations

\begin{tabular}{c|cc|cc}
\hline Obs. level & \multicolumn{2}{|c|}{ Firm-mkt } & \multicolumn{2}{c}{ Firm-prod-mkt } \\
\hline duration & Spells & Obs. & Spells & Obs. \\
\hline 1 & 0.34 & 0.09 & 0.51 & 0.26 \\
2 & 0.10 & 0.06 & 0.10 & 0.10 \\
3 & 0.05 & 0.04 & 0.04 & 0.06 \\
4 & 0.03 & 0.03 & 0.02 & 0.04 \\
5 & 0.02 & 0.03 & 0.01 & 0.03 \\
6 & 0.01 & 0.02 & 0.01 & 0.02 \\
$7+$ & 0.06 & 0.17 & 0.02 & 0.11 \\
\hline Left cens. & 0.25 & 0.45 & 0.17 & 0.28 \\
Right cens. & 0.14 & 0.10 & 0.11 & 0.11 \\
\hline $\mathrm{N}$ & 55,131 & 187,409 & 262,969 & 526,438 \\
\hline
\end{tabular}

Notes: Table reports share of relevant unit of observation (export spells, or export observations) with given duration, for data at the firm-product-market level, and data aggregated to the firm-market level. Source: CSO and authors' calculations.

Table 5: Regression of duration on $m^{i}$ and $f^{k}$

\begin{tabular}{ccc}
\hline & coeff & s.e. \\
\hline$m^{i}$ & 0.40 & $(0.01)^{* *}$ \\
$f^{k}$ & 0.62 & $(0.02)^{* *}$ \\
\hline $\mathrm{N}$ & \multicolumn{2}{c}{188,435} \\
$\mathrm{R}^{2}$ & \multicolumn{2}{c}{0.006} \\
\hline
\end{tabular}

Notes: Dependent variable is duration. Observations are at the firm-product-market spell level. Duration is top-coded at 7. Left- and right-censored spells are excluded. Source: CSO and authors' calculations. 
Table 6: Dynamics of revenue, quantity, price, and number of products

\begin{tabular}{|c|c|c|c|c|c|c|c|c|}
\hline Obs. level & \multicolumn{4}{|c|}{ Firm-product-market } & \multicolumn{4}{|c|}{ Firm-market } \\
\hline Dep. var. $(\ln )$ & Revenue & Quantity & \multicolumn{2}{|c|}{ Price } & \multicolumn{2}{|c|}{ Revenue } & \multicolumn{2}{|c|}{ \# Products } \\
\hline Duration & \multicolumn{8}{|c|}{ Spell intercept } \\
\hline 2 years & $(0.04)^{* *}$ & $(0.04)^{* *}$ & -0.02 & $(0.02)$ & 0.49 & $(0.06)^{* *}$ & 0.10 & $(0.01)^{* *}$ \\
\hline 3 years & $(0.05)^{* *}$ & $(0.06)^{* *}$ & 0.00 & $(0.03)$ & 0.83 & $(0.07)^{* *}$ & 0.15 & $(0.02)^{* *}$ \\
\hline 4 years & $(0.07)^{* *}$ & $(0.07)^{* *}$ & 0.01 & $(0.04)$ & 1.03 & $(0.09)^{* *}$ & 0.21 & $(0.02)^{* *}$ \\
\hline 5 years & $(0.09)^{* *}$ & $(0.10)^{* *}$ & -0.02 & $(0.05)$ & 1.20 & $(0.11)^{* *}$ & 0.21 & $(0.02)^{* *}$ \\
\hline 6 years & $(0.12)^{* *}$ & $(0.12)^{* *}$ & 0.00 & $(0.05)$ & 1.33 & $(0.12)^{* *}$ & 0.28 & $(0.03)^{* *}$ \\
\hline $7+$ years & $(0.07)^{* *}$ & $(0.07)^{* *}$ & -0.05 & $(0.03)$ & 1.55 & $(0.06)^{* *}$ & 0.30 & $(0.01)^{* *}$ \\
\hline left-cens & $(0.03)^{* *}$ & $(0.03)^{* *}$ & -0.05 & $(0.02)^{* *}$ & 3.50 & $(0.03)^{* *}$ & 0.72 & $(0.01)^{* *}$ \\
\hline right-cens & $(0.04)^{* *}$ & $(0.04)^{* *}$ & 0.01 & $(0.02)$ & 1.82 & $(0.04)^{* *}$ & 0.31 & $(0.01)^{* *}$ \\
\hline Tenure & \multicolumn{8}{|c|}{ 2-year spell } \\
\hline 2 years & $(0.05)$ & $(0.05)$ & 0.00 & $(0.03)$ & -0.09 & $(0.07)$ & 0.00 & $(0.02)$ \\
\hline Tenure & \multicolumn{8}{|c|}{ 3-year spell } \\
\hline 2 years & $(0.07)^{* *}$ & $(0.07)^{* *}$ & -0.01 & $(0.04)$ & 0.46 & $(0.09)^{* *}$ & 0.10 & $(0.02)^{* *}$ \\
\hline 3 years & $(0.07)$ & $(0.07)^{*}$ & 0.02 & $(0.04)$ & 0.05 & $(0 . .09)$ & 0.01 & $(0.02)$ \\
\hline Tenure & \multicolumn{8}{|c|}{ 4-year spell } \\
\hline 2 years & $(0.10)^{* *}$ & $(0.10)^{* *}$ & -0.06 & $(0.05)$ & 0.61 & $(0.12)^{* *}$ & 0.12 & $(0.03)^{* *}$ \\
\hline 3 years & $(0.09)^{* *}$ & $(0.10)^{* *}$ & -0.05 & $(0.05)$ & 0.56 & $(0.12)^{* *}$ & 0.10 & $(0.03)^{* *}$ \\
\hline 4 years & $(0.10)$ & $(0.10)$ & 0.01 & $(0.05)$ & 0.25 & $(0.12)^{* *}$ & 0.00 & $(0.03)$ \\
\hline Tenure & \multicolumn{8}{|c|}{5 -year spell } \\
\hline 2 years & $(0.13)^{* *}$ & $(0.13)^{* *}$ & -0.01 & $(0.06)$ & 0.64 & $(0.15)^{* *}$ & 0.14 & $(0.03)^{* *}$ \\
\hline 3 years & $(0.13)^{* *}$ & $(0.13)^{* *}$ & 0.01 & $(0.06)$ & 0.70 & $(0.15)^{* *}$ & 0.15 & $(0.04)^{* *}$ \\
\hline 4 years & $(0.13)^{* *}$ & $(0.13)^{* *}$ & -0.01 & $(0.06)$ & 0.52 & $(0.14)^{* *}$ & 0.13 & $(0.04)^{* *}$ \\
\hline 5 years & $(0.13)$ & $(0.14)$ & 0.03 & $(0.06)$ & 0.01 & $(0.15)$ & 0.04 & $(0.03)$ \\
\hline Tenure & \multicolumn{8}{|c|}{ 6-year spell } \\
\hline 2 years & $(0.15)^{* *}$ & $(0.16)^{* *}$ & -0.03 & $(0.07)$ & 0.58 & $(0.15)^{* *}$ & 0.17 & $(0.04)^{* *}$ \\
\hline 3 years & $(0.15)^{* *}$ & $(0.16)^{* *}$ & -0.09 & $(0.07)$ & 0.78 & $(0.15)^{* *}$ & 0.17 & $(0.04)^{* *}$ \\
\hline 4 years & $(0.15)^{* *}$ & $(0.16)^{* *}$ & -0.02 & $(0.07)$ & 0.87 & $(0.15)^{* *}$ & 0.22 & $(0.04)^{* *}$ \\
\hline 5 years & $(0.15)^{* *}$ & $(0.16)^{* *}$ & 0.01 & $(0.07)$ & 0.62 & $(0.16)^{* *}$ & 0.13 & $(0.04)^{* *}$ \\
\hline 6 years & $(0.16)$ & $(0.17)$ & 0.02 & $(0.08)$ & -0.05 & $(0.16)$ & -0.02 & $(0.04)$ \\
\hline Tenure & \multicolumn{8}{|c|}{$7+$ year spell } \\
\hline 2 years & $(0.08)^{* *}$ & $(0.09)^{* *}$ & 0.00 & $(0.04)$ & 1.00 & $(0.07)^{* *}$ & 0.20 & $(0.02)^{* *}$ \\
\hline 3 years & $(0.08) * *$ & $(0.09)^{* *}$ & -0.05 & $(0.04)$ & 1.30 & $(0.07)^{* *}$ & 0.26 & $(0.02)^{* *}$ \\
\hline 4 years & $(0.09)^{* *}$ & $(0.09)^{* *}$ & -0.01 & $(0.04)$ & 1.44 & $(0.07)^{* *}$ & 0.29 & $(0.02)^{* *}$ \\
\hline 5 years & $(0.08) * *$ & $(0.09)^{* *}$ & -0.01 & $(0.04)$ & 1.52 & $(0.07)^{* *}$ & 0.30 & $(0.02)^{* *}$ \\
\hline 6 years & $(0.09)^{* *}$ & $(0.09)^{* *}$ & -0.03 & $(0.04)$ & 1.44 & $(0.07)^{* *}$ & 0.28 & $(0.02)^{* *}$ \\
\hline $7+$ years & $(0.08)^{* *}$ & $(0.08)^{* *}$ & -0.04 & $(0.02)^{* *}$ & 1.54 & $(0.06)^{* *}$ & 0.31 & $(0.02)^{* *}$ \\
\hline Fixed effects & fpy \& pmy & fpy \& pmy & \multicolumn{2}{|c|}{ fpy \& pmy } & \multicolumn{2}{|c|}{ fy \& my } & \multicolumn{2}{|c|}{ fy \& my } \\
\hline $\mathrm{N}$ & \multirow{3}{*}{$\begin{array}{c}183,831 \\
0.74 \\
0.59\end{array}$} & \multirow{3}{*}{$\begin{array}{c}183,831 \\
0.81 \\
0.69\end{array}$} & \multirow{3}{*}{\multicolumn{2}{|c|}{$\begin{array}{c}183,831 \\
0.87 \\
0.79\end{array}$}} & \multirow{3}{*}{\multicolumn{2}{|c|}{$\begin{array}{c}174,341 \\
0.56 \\
0.51\end{array}$}} & \multirow{3}{*}{\multicolumn{2}{|c|}{$\begin{array}{c}174,341 \\
0.47 \\
0.42\end{array}$}} \\
\hline $\mathrm{R}^{2}$ & & & & & & & & \\
\hline $\mathrm{R}^{2}$-adj & & & & & & & & \\
\hline
\end{tabular}

Notes: Table reports fitted values based on regression of relevant dependent variable on combinations of indicator variables for spell duration and tenure, these indicator variables interacted with $m^{i}$ and $f^{k}$, and firm-product-year and market-product-year or firm-year and market-year fixed effects as appropriate. Omitted category is spells that last one year. Fitted values evaluated at mean of $m^{i}$ and $f^{k}$. Dependent variable in first three columns is in turn log revenue, $\log$ quantity, and log price at the firm-product-market-year level. In the first column, the sample is restricted to firm-product-market-years for which quantity data are available. Dependent variables in fourth and fifth columns are log revenue and log number of products at the firmmarket-year level. Robust standard errors calculated. ** significant at 5\%, * significant at 10\%. Source: CSO and authors' calculations. 
Table 7: Exit hazard

\begin{tabular}{r|cc|cc}
\hline Obs. level & \multicolumn{3}{|c}{ Firm-prod-mkt } & \multicolumn{2}{|c}{ Firm-mkt } \\
\hline & \multicolumn{4}{|c}{ Tenure } \\
\hline 2 years & -0.13 & $(0.01)^{* *}$ & -0.16 & $(0.01)^{* *}$ \\
3 years & -0.20 & $(0.01)^{* *}$ & -0.24 & $(0.01)^{* *}$ \\
4 years & -0.24 & $(0.01)^{* *}$ & -0.26 & $(0.01)^{* *}$ \\
5 years & -0.24 & $(0.01)^{* *}$ & -0.29 & $(0.01)^{* *}$ \\
6 years & -0.24 & $(0.01)^{* *}$ & -0.29 & $(0.01)^{* *}$ \\
\hline 7+ years & -0.27 & $(0.01)^{* *}$ & -0.32 & $(0.01)^{* *}$ \\
\hline cens & -0.27 & $(0.01)^{* *}$ & -0.34 & $(0.00)^{* *}$ \\
\hline Fixed effects & fpy \& pmy & \multicolumn{2}{|c}{ fy \& my } \\
\hline $\mathrm{N}$ & \multicolumn{2}{|c|}{171,683} & \multicolumn{2}{|c}{162,640} \\
$\mathrm{R}^{2}$ & \multicolumn{2}{|c}{0.66} & \multicolumn{2}{|c}{0.41} \\
$\mathrm{R}^{2}$-adj & \multicolumn{2}{|c}{0.46} & \multicolumn{2}{|c}{0.35} \\
\hline
\end{tabular}

Notes: Table reports fitted values based on regression of an indicator for exit in the next period on indicators for tenure, indicators for tenure interacted with $m^{i}$ and $f^{k}$ and firm-product-year and market-product-year or firm-year and market-year fixed effects as appropriate. Omitted category is market tenure equal to one year. Fitted values evaluated at mean of $m^{i}$ and $f^{k}$. Robust standard errors calculated. ${ }^{* *}$ significant at $5 \%,{ }^{*}$ significant at $10 \%$. Source: CSO and authors' calculations.

Table 8: Entry and 1-year exit

\begin{tabular}{|c|c|c|}
\hline Obs. level & Firm-prod-mkt & Firm-mkt \\
\hline & Entry & Entry \\
\hline & $0.007 \quad(0.000)^{* *}$ & $0.065 \quad(0.000)^{* *}$ \\
\hline $\mathrm{N}$ & $127,683,042$ & $8,501,296$ \\
\hline \multirow[t]{3}{*}{$\mathrm{R}^{2}$} & 0.005 & 0.046 \\
\hline & 1-yr Exit & 1-yr Exit \\
\hline & $0.68 \quad(0.00)^{* *}$ & $0.44 \quad(0.00)^{* *}$ \\
\hline $\mathrm{N}$ & 184,602 & 37,802 \\
\hline $\mathrm{R}^{2}$ & 0.01 & 0.04 \\
\hline
\end{tabular}

Notes: Table reports fitted values based on regression of indicator for future entry or indicator for future exit on $m^{i}$ and $f^{k}$, evaluated at means of $m^{i}$ and $f^{k}$. Sample in firm-product-market entry equation includes all firm-product-markets which do not currently have positive exports, but for which the firm currently exists in the data, and for which the firm exports the relevant product to at least one destination for at least one year in the sample. Sample in firm-market entry equation includes all firm-markets which do not currently have positive exports, but for which the firm currently exists in the data. Sample in one-year exit equations includes all relevant observations where tenure equals one year. Robust standard errors calculated. ${ }^{* *}$ significant at $5 \%, *$ significant at $10 \%$. Source: CSO and authors' calculations. 
Table 9: Building our specification: Quantity

\begin{tabular}{|c|c|c|c|c|c|}
\hline & (1) & $(2)$ & $(3)$ & (4) & $(5)$ \\
\hline & duration & tenure, exit & dur, tenure, exit & dur $\times$ tenure & baseline \\
\hline & \multicolumn{3}{|c|}{ duration } & \multicolumn{2}{|c|}{ duration at tenure $=1$} \\
\hline 2 yrs & $(0.03)^{* *}$ & & $(0.03)^{* *}$ & $0.50 \quad(0.04)^{* *}$ & $0.57 \quad(0.04)^{* *}$ \\
\hline 3 yrs & $0.83 \quad(0.03)^{* *}$ & & $(0.04)^{* *}$ & $0.74 \quad(0.05)^{* *}$ & $0.86 \quad(0.06)^{* *}$ \\
\hline 4 yrs & $1.10(0.04)^{* *}$ & & $(0.05)^{* *}$ & $(0.07)^{* *}$ & $(0.07)^{* *}$ \\
\hline $5 \mathrm{yrs}$ & $1.31(0.04)^{* *}$ & & $(0.06)^{* *}$ & $(0.09)^{* *}$ & $(0.10)^{* *}$ \\
\hline 6 yrs & $1.51(0.05)^{* *}$ & & $(0.06)^{* *}$ & $(0.11)^{* *}$ & $(0.12)^{* *}$ \\
\hline \multirow[t]{2}{*}{$7+\mathrm{yrs}$} & $2.26 \quad(0.03)^{* *}$ & & $(0.06)$ & $(0.07)^{* *}$ & $1.42(0.07)^{* *}$ \\
\hline & \multicolumn{3}{|c|}{ tenure } & \multicolumn{2}{|c|}{ tenure at duration $=7+$} \\
\hline $2 \mathrm{yrs}$ & & $0.61 \quad(0.02)^{* *}$ & $(0.03)^{* *}$ & $0.86 \quad(0.08)^{* *}$ & $0.80 \quad(0.09)^{* *}$ \\
\hline 3 yrs & & $0.93(0.03)^{* *}$ & $(0.04)^{* *}$ & $(0.08)^{* *}$ & $(0.09)^{* *}$ \\
\hline 4 yrs & & $1.18(0.04)^{* *}$ & $(0.05)^{* *}$ & $(0.08)^{* *}$ & $(0.09)^{* *}$ \\
\hline 5 yrs & & $1.37(0.04)^{* *}$ & $(0.05)^{* *}$ & $(0.08)^{* *}$ & $(0.09)^{* *}$ \\
\hline 6 yrs & & $1.53(0.05)^{* *}$ & $(0.06)^{* *}$ & $(0.09)^{* *}$ & $(0.09)^{* *}$ \\
\hline $7+\mathrm{yrs}$ & & $1.79 \quad(0.05)^{* *}$ & $1.49 \quad(0.06)^{* *}$ & $1.32(0.08)^{* *}$ & $(0.08)^{* *}$ \\
\hline l-cens & $2.61 \quad(0.03)^{* *}$ & $1.85 \quad(0.03)^{* *}$ & $1.63(0.04)^{* *}$ & $2.62 \quad(0.03)^{* *}$ & $2.75 \quad(0.03)^{* *}$ \\
\hline r-cens & $1.22(0.04)^{* *}$ & & $-0.37 \quad(0.05)^{* *}$ & $1.32(0.04)^{* *}$ & $1.54 \quad(0.04)^{* *}$ \\
\hline Exit & & $-1.13(0.02)^{* *}$ & $-1.25 \quad(0.03)^{* *}$ & & \\
\hline f.e. & fpy \& pmy & fpy \& pmy & fpy \& pmy & fpy \& pmy & fpy \& pmy \\
\hline $\begin{array}{r}\mathrm{N} \\
\mathrm{R}^{2}\end{array}$ & $\begin{array}{c}183,831 \\
0.80\end{array}$ & $\begin{array}{c}171,683 \\
0.81\end{array}$ & $\begin{array}{c}171,683 \\
0.81\end{array}$ & $\begin{array}{c}183,831 \\
0.81\end{array}$ & $\begin{array}{c}183,831 \\
0.81\end{array}$ \\
\hline
\end{tabular}

Notes: Dependent variable is log quantity at the firm-product-market level. All equations include firm-product-year and product-market-year fixed effects. Equation (4) includes full set of duration-tenure interactions and reports only a subset of results. Equation (5) reports a subset of the coefficients from our baseline specification as in Table 6. Robust standard errors calculated. ${ }^{* *}$ significant at $5 \%, *$ significant at $10 \%$. Source: CSO and authors' calculations. 
Table 10: Building our specification: Price

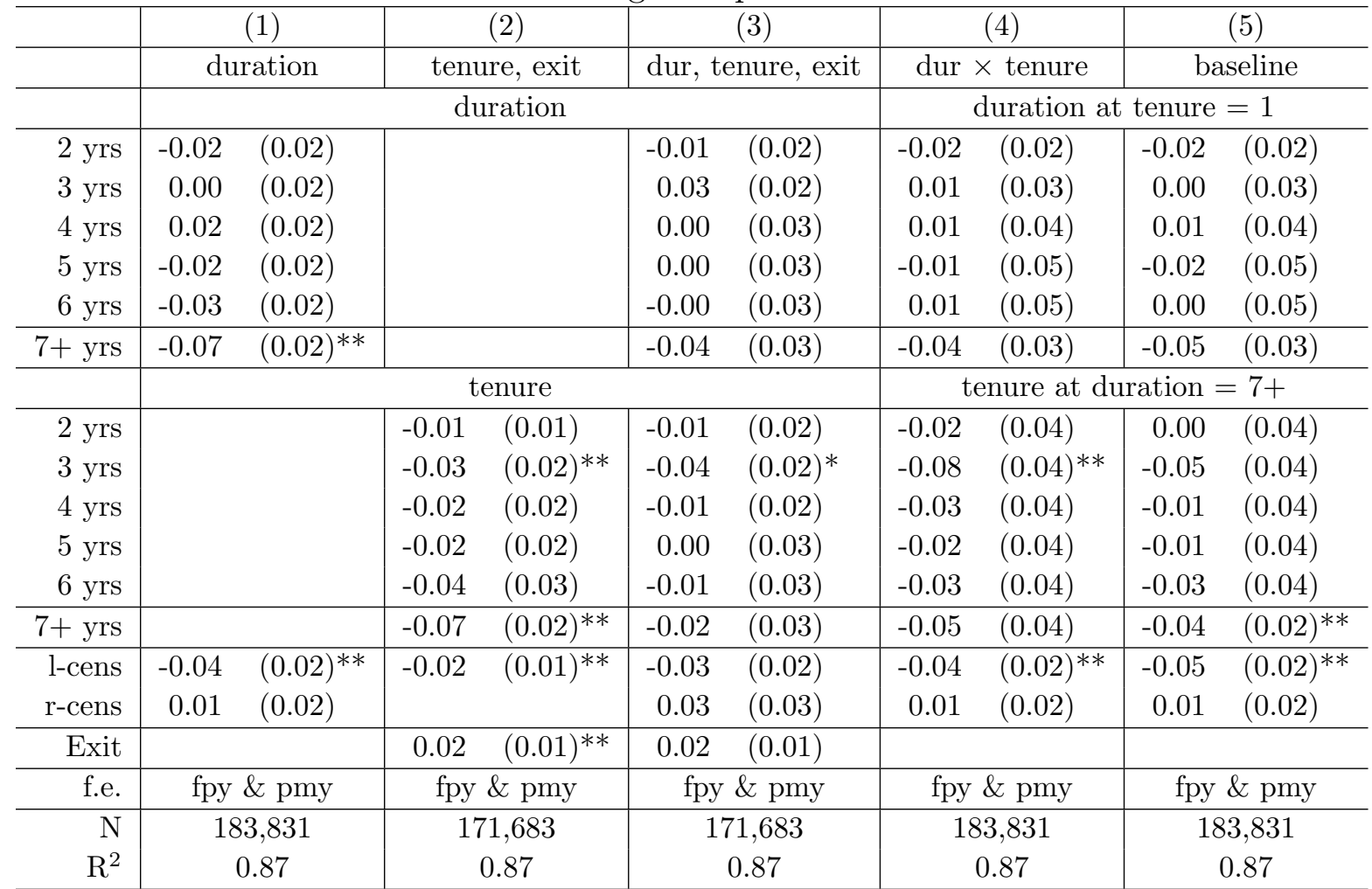

Notes: Dependent variable is log price at the firm-product-market level. All equations include firm-product-year and productmarket-year fixed effects. Equation (4) includes full set of duration-tenure interactions and reports only a subset of results. Equation (5) reports a subset of the coefficients from our baseline specification as in Table 6. Robust standard errors calculated. ** significant at $5 \%,{ }^{*}$ significant at $10 \%$. Source: CSO and authors' calculations.

Table 11: Dynamics of prices: Alternative specifications

\begin{tabular}{|c|c|c|c|c|c|c|c|c|}
\hline & & (1) & & $(2)$ & & (3) & & $(4)$ \\
\hline Tenure & \multicolumn{2}{|c|}{ Foster et al. } & \multicolumn{2}{|c|}{ Piveteau (2016) } & \multicolumn{2}{|c|}{ Piveteau (2019) } & \multicolumn{2}{|c|}{ Berman et al. } \\
\hline 2 years & 0.03 & $(0.01)^{* *}$ & 0.03 & $(0.05)$ & -0.01 & $(0.01)$ & -0.01 & $(0.01)$ \\
\hline 3 years & 0.04 & $(0.01)^{* *}$ & 0.07 & $(0.05)$ & -0.03 & $(0.02)^{* *}$ & -0.01 & $(0.01)$ \\
\hline 4 years & 0.06 & $(0.02)^{* *}$ & 0.12 & $(0.06)^{* *}$ & -0.02 & $(0.02)$ & -0.01 & $(0.02)$ \\
\hline 5 years & 0.03 & $(0.02)$ & 0.10 & $(0.07)$ & -0.02 & $(0.02)$ & -0.00 & $(0.02)$ \\
\hline 6 years & 0.02 & $(0.03)$ & 0.11 & $(0.08)$ & -0.04 & $(0.03)$ & -0.01 & $(0.02)$ \\
\hline $7+$ years & -0.04 & $(0.02)^{* *}$ & 0.10 & $(0.10)$ & -0.07 & $(0.02)^{* *}$ & -0.07 & $(0.02)^{* *}$ \\
\hline cens & 0.04 & $(0.01)^{* *}$ & 0.14 & $(0.10)$ & -0.02 & $(0.01)^{* *}$ & -0.03 & $(0.03)$ \\
\hline \multirow[t]{2}{*}{ exit } & -0.06 & $(0.01)^{* *}$ & & & 0.02 & $(0.01)^{* *}$ & & \\
\hline & \multicolumn{8}{|c|}{ Fixed effects } \\
\hline Firm-prod-yr & \multirow{2}{*}{\multicolumn{2}{|c|}{$\begin{array}{l}\text { No } \\
\text { Yes }\end{array}$}} & & & & & \multirow{2}{*}{\multicolumn{2}{|c|}{$\begin{array}{l}\text { Yes } \\
\text { No }\end{array}$}} \\
\hline Prod-mkt-yr & & & \multicolumn{2}{|c|}{ Yes } & \multicolumn{2}{|c|}{ Yes } & & \\
\hline $\mathrm{N}$ & \multicolumn{2}{|c|}{253,398} & \multicolumn{2}{|c|}{71545} & \multicolumn{2}{|c|}{171,683} & \multicolumn{2}{|c|}{265194} \\
\hline $\mathrm{R}^{2}$ & \multicolumn{2}{|c|}{0.69} & \multicolumn{2}{|c|}{0.87} & \multicolumn{2}{|c|}{0.87} & \multicolumn{2}{|c|}{0.85} \\
\hline
\end{tabular}

Notes: Dependent variable is log price at the firm-product-market-year level. Specification in column (1) is based on Foster et al. (2008). Standard errors are clustered at the firm-product-market level. Specification in colunn (2) is based on Piveteau (2016). In this case, the sample is restricted to spells lasting 7+ years. Standard errors are clustered at the firm-product-market level. Specification in column (3) is based on Piveteau (2019). Specification in column (4) is based on Berman et al. (2019). Standard errors are clustered at the firm level. Omitted category is observations where tenure $=1 .{ }^{* *}$ significant at $5 \%, *$ significant at $10 \%$. Source: CSO and authors' calculations. 
Table 12: Structural models: parameters and fit

\begin{tabular}{c|cccccccccccc|c}
\hline & $\sigma_{\nu}$ & $\sigma_{\eta}$ & $\rho$ & $\lambda$ & $F^{\dagger}$ & $\omega$ & $\gamma$ & $\underline{D}^{\S}$ & $\alpha$ & $\delta$ & $\phi$ & $\theta$ & $m^{\prime} V m$ \\
\hline $\mathrm{Adv}$ & 0.43 & 0.24 & 0.90 & 0.05 & 0.21 & 0.02 & 0.73 & 0.24 & 0.51 & 0.73 & 0.28 & n.a. & 2.52 \\
s.e. & 0.00 & 0.00 & 0.00 & 0.00 & n.a. & 0.00 & 0.00 & n.a. & 0.00 & 0.00 & 0.00 & n.a. & \\
\hline $\mathrm{CM}$ & 0.36 & 0.84 & 0.09 & 0.04 & 0.01 & 0.04 & 0.26 & 0.25 & 0.69 & 0.79 & n.a. & 31.9 & 4.56 \\
s.e. & 0.00 & 0.00 & 0.00 & 0.00 & n.a. & 0.00 & 0.00 & n.a. & 0.00 & 0.00 & n.a. & 0.0 & \\
\hline
\end{tabular}

Notes: $\dagger$ The value reported here for the marketing and advertising model is the average ratio of $F_{t}^{i k}$ to revenue net of total marginal cost across all participants in their first period (6 months) of participation. This includes participants for whom $F_{t}^{i k}=0$. The value for the customer markets model is the average ratio of $F_{t}^{i k}$ to revenue. The estimate of the parameter governing $F$ in the marketing and advertising model is 0.3316 and the standard error is 0.000 . The estimate of the parameter governing $F$ in the customer markets model is 0.2327 and the standard error is $0.000 . \S$ The value reported here is the average of $D / R_{13}$ across all participants who survive 13 periods in the market, where $R_{13}$ is revenue in period 13 . The estimate of the parameter governing $D$ in the advertising model is 0.0393 and the associated standard error is 0.0000 . The estimate of the parameter governing $\underline{D}$ in the customer markets model is 0.0135 and the associated standard error is 0.0000 . "Fit" is the value of the criterion function, $m^{\prime} V m$, where $m$ is the difference between data moments and moments of the model conditional on the parameter vector, and $V$ is a diagonal matrix with the vector of inverses of the standard errors of the data moments on the diagonal. Standard errors are calculated following Gourieroux et al. as described in Appendix E.

Figure 1: Estimated quantity trajectories

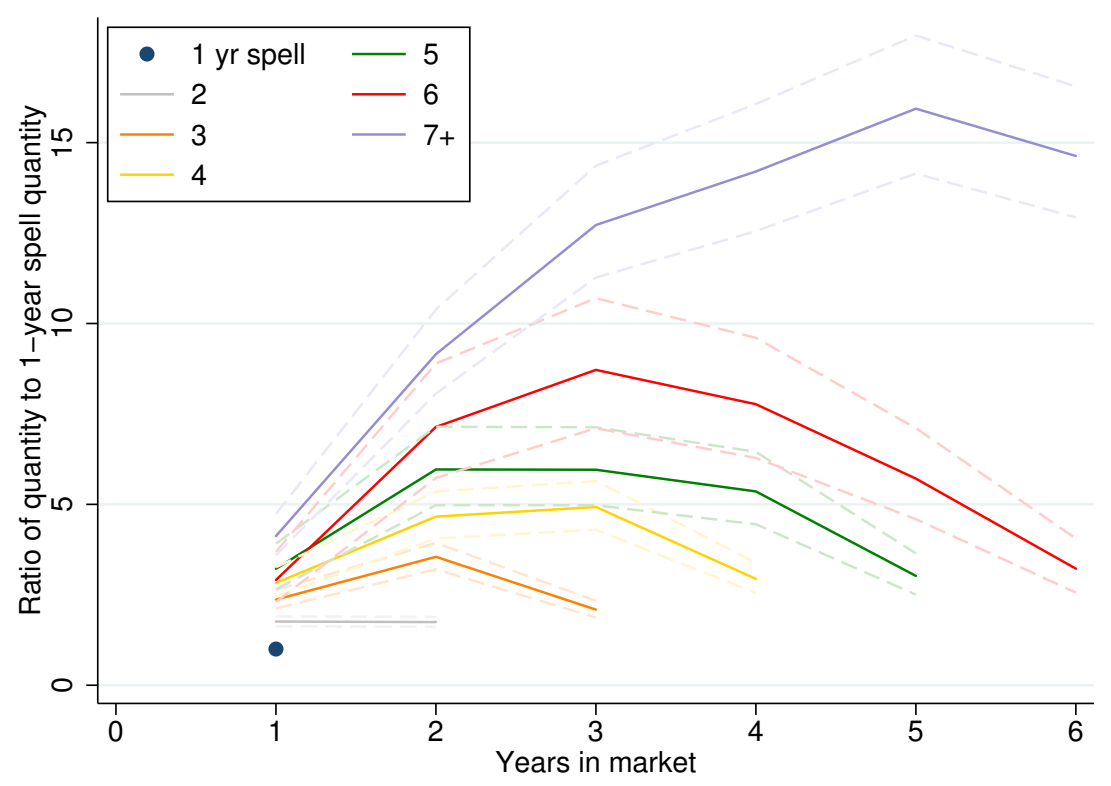

Notes: Figure shows evolution of quantities at the firm-product-market level with market tenure, allowing trajectories to differ by export spell duration. Trajectories are conditional on firm-product-year and market effects. 95\% confidence intervals are plotted. Source: CSO and authors' calculations. 
Figure 2: Estimated price trajectories

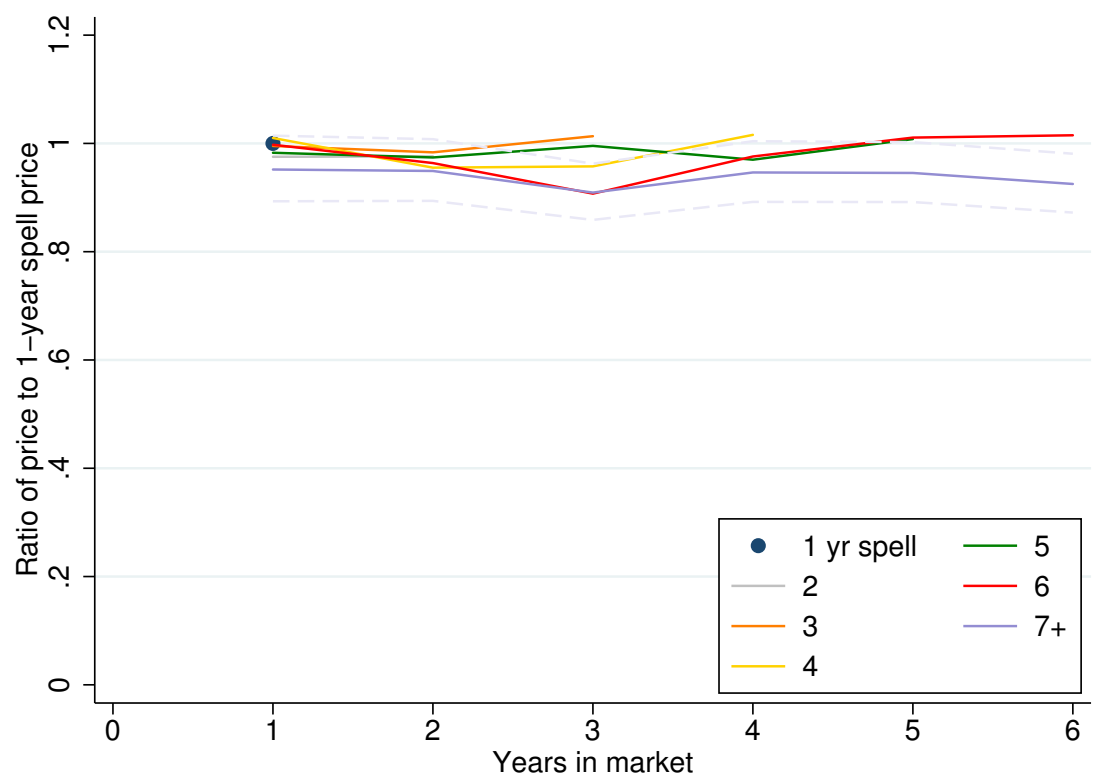

Notes: Figure shows evolution of prices at the firm-product-market level with market tenure, allowing trajectories to differ by export spell duration. Trajectories are conditional on firm-product-year and market effects. 95\% confidence interval for spells of $7+$ years is plotted. Source: CSO and authors' calculations.

\section{Figure 3: Estimated exit trajectories}

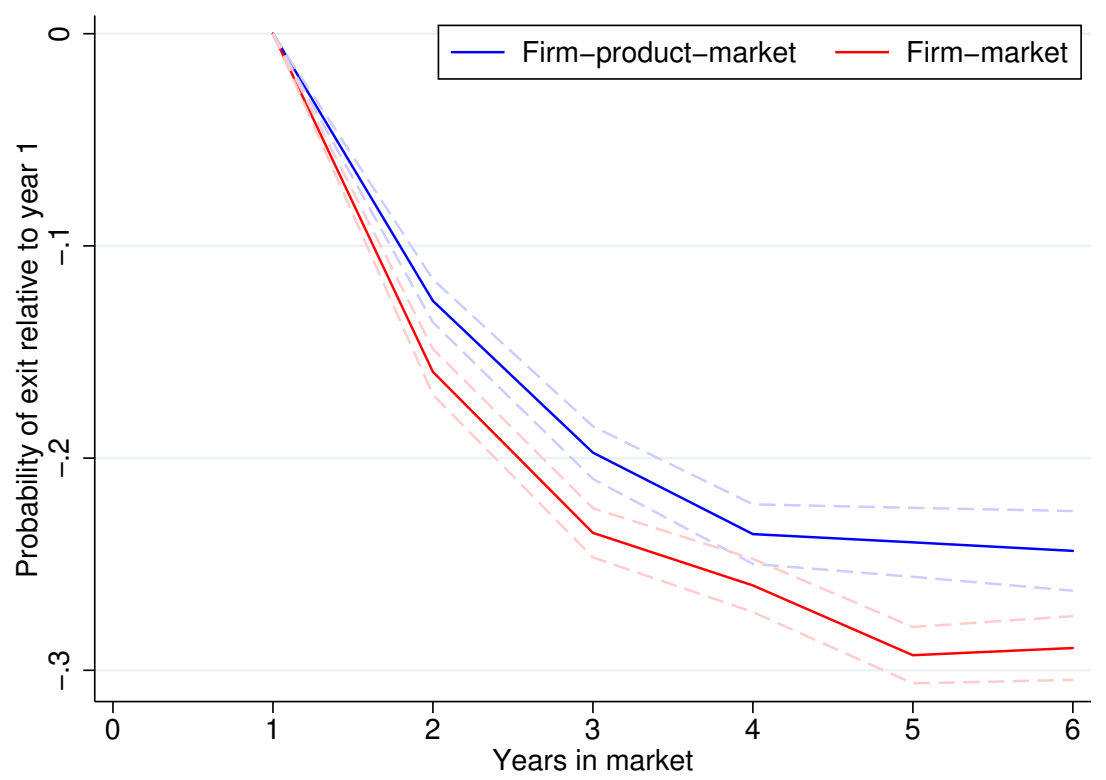

Notes: Figure shows reduction in probability of exit at the firm-market and firm-product-market levels with compared to probability of exit in the first year in a market. Trajectories are conditional on firm-year and market and firm-product-year and market effects, respectively. 95\% confidence intervals are plotted. Source: CSO and authors' calculations. 
Figure 4: Model fit: Quantities
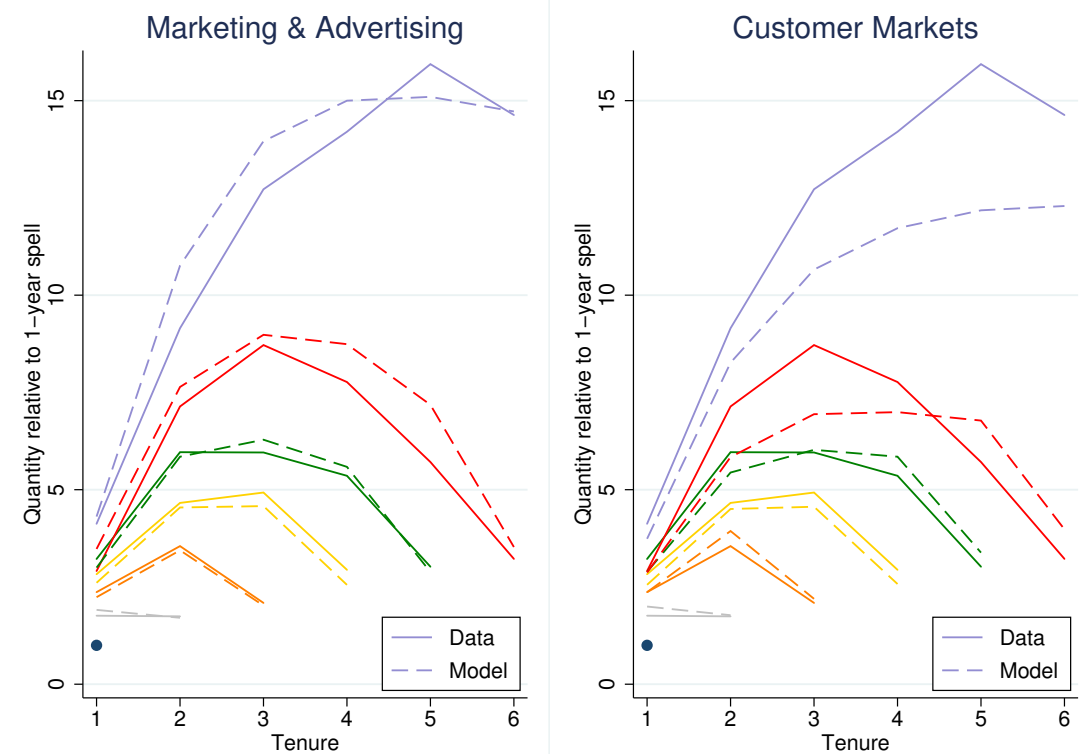

Notes: Figure shows evolution of quantities with tenure, for spells of different duration. Data is from Figure 1. Left panel shows corresponding quantity trajectories for the marketing and mdvertising model. Right panel shows corresponding quantity trajectories for the customer markets model. All quantities are expressed relative to the quantity in a 1-year spell. Source: CSO and authors' calculations.

Figure 5: Model fit: Prices
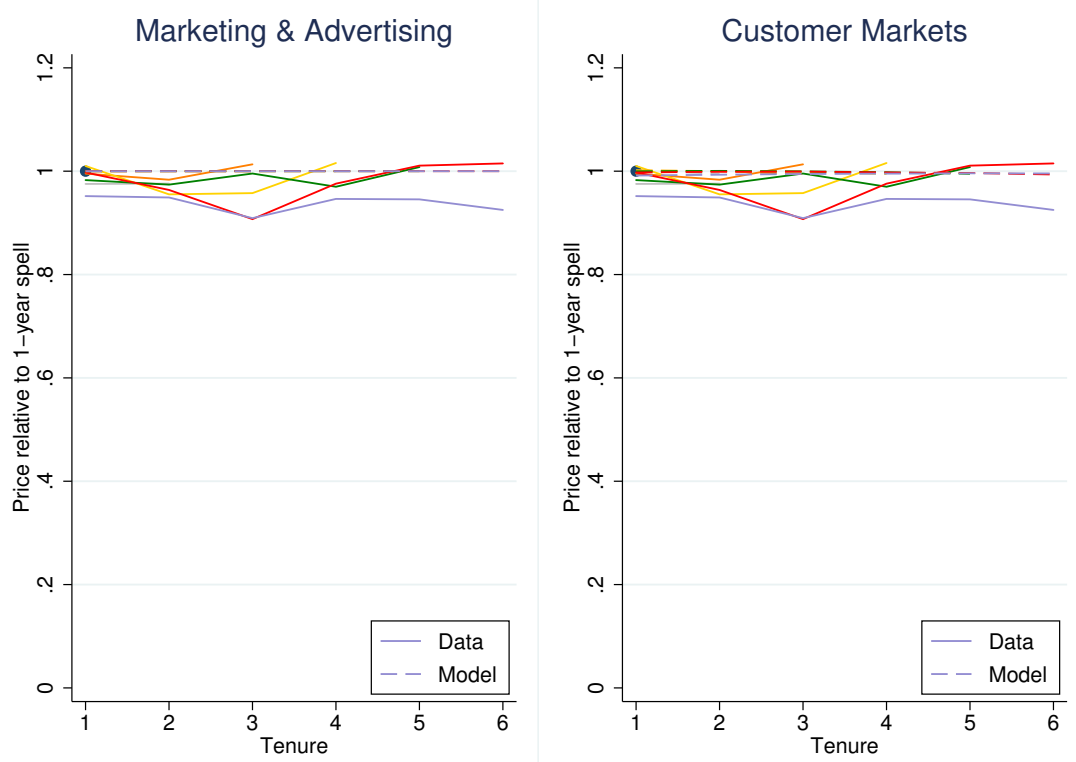

Notes: Figure shows evolution of prices with tenure, for spells of different duration. Data is from Figure 2. Left panel shows corresponding price trajectories for the marketing and advertising model. Right panel shows corresponding price trajectories for the customer markets model. All prices are expressed relative to the price in a 1-year spell. Source: CSO and authors' calculations. 
Figure 6: Model fit: Exit
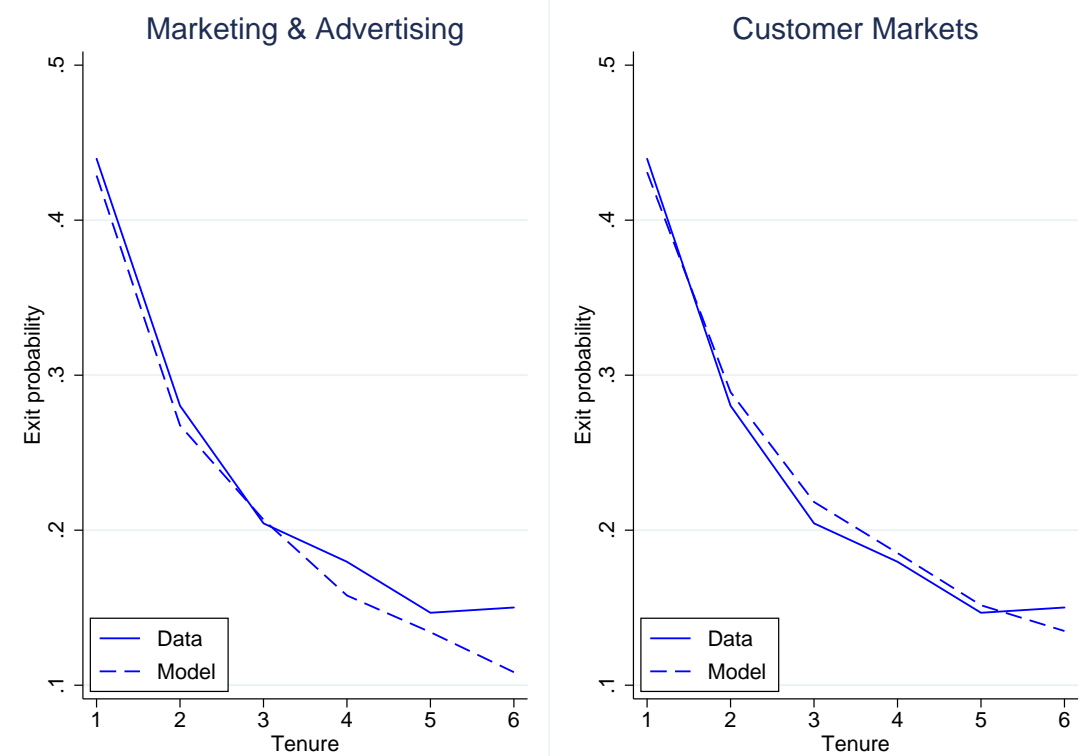

Notes: Figure shows evolution of probability of exit with tenure. Data (at the firm-market level) is from Figure 7 . Left panel shows corresponding evolution of exit probability for the marketing and advertising model. Right panel shows corresponding evolution of exit probability for the customer markets model. Source: CSO and authors' calculations.

Figure 7: Selling expenses as a share of revenue net of variable cost

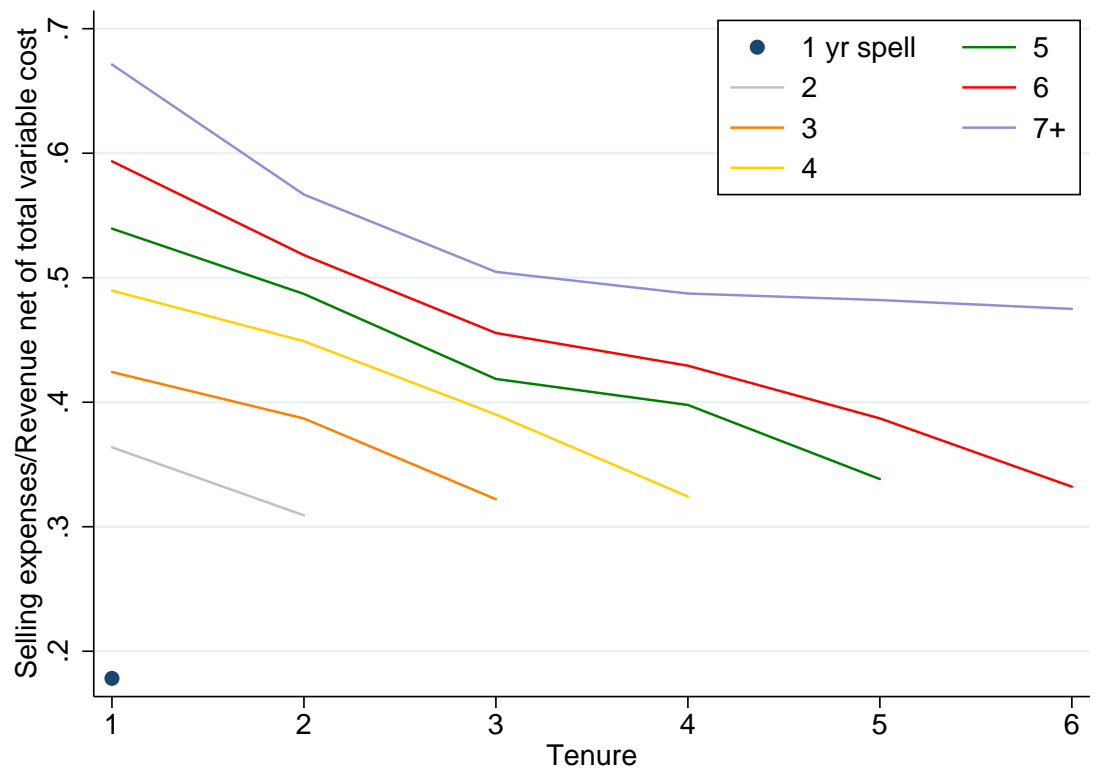

Notes: Figure shows average ratio of selling expenses to revenue less total variable cost predicted by the marketing and advertising model for export spells of different length. Source: Authors' calculations. 